\title{
Crustaceans of Mermaid (Rowley Shoals), Scott and Seringapatam Reefs, north Western Australia
}

\author{
M.A. Titelius, A. Sampey, and C.G. Hass
}

\begin{abstract}
The atolls on the north-western Australian continental shelf are recognised in having a diverse shallow-water fauna with many widely distributed Indo-West Pacific species. However, the crustaceans of these reefs are poorly known. A survey of the crustaceans of four of the reefs on these continental-shelf atolls (Mermaid, South and North Scott, and Seringapatam reefs) was conducted in 2006 by the Western Australian Museum, Perth. Identifications focused on the stomatopod and decapod crustaceans, although many species within these groups such as the galatheids, caridean shrimps, and stomatopods, are not yet fully identified. A total of 157 species were recorded, more than doubling the numbers of species previously recorded from these atolls. The number of species will increase with identification of the unidentified specimens. The Xanthidae (Brachyura) was the most diverse family at all reefs, which is typical of Australian coastal waters. Differences in the stomatopods and decapod assemblages among reefs and respective habitats are discussed.
\end{abstract}

\section{INTRODUCTION}

Along the edge of the continental shelf of northwestern Australia are a series of emergent reefs, from north to south these are: Ashmore Reef $\left(12^{\circ} 10^{\prime} \mathrm{S} 122^{\circ} 58^{\prime} \mathrm{E}\right)$, Cartier Island (12 $\left.{ }^{\circ} 31^{\prime} \mathrm{S} 123^{\circ} 33^{\prime} \mathrm{E}\right)$, Hibernia Reef $\left(11^{\circ} 55^{\prime} \mathrm{S} 123^{\circ} 28^{\prime} \mathrm{E}\right)$, Seringapatam Reef $\left(13^{\circ} 38^{\prime} \mathrm{S} 122^{\circ} 05^{\prime} \mathrm{E}\right)$, North and South Scott reefs $\left(13^{\circ} 59^{\prime} \mathrm{S} 121^{\circ} 46^{\prime} \mathrm{E}\right)$ and the Rowley Shoals (Mermaid, $17^{\circ} 07^{\prime} \mathrm{S} 119^{\circ} 36^{\prime} \mathrm{E}$; Clerke, $17^{\circ} 10^{\prime} \mathrm{S} 119^{\circ} 20^{\prime} \mathrm{E}$; and Imperieuse, $17^{\circ} 35^{\prime} \mathrm{S} 118^{\circ} 56^{\prime} \mathrm{E}$, reefs). These reefs have been recognised for their regional importance in providing habitat for shallow water coral reef fauna along the north-western Australian coast (Berry and Marsh, 1986). The stomatopod and decapod crustacean faunas of these reefs are poorly known as very few collections have been made.

A Western Australian Museum (WA Museum) expedition to Ashmore Reef and Cartier Island in 1986 recorded 93 decapod crustaceans (Morgan and Berry, 1993). The collections were dominated by xanthoids ( 39 species) and paguroids ( 25 species) (Morgan and Berry, 1993). The crustacean fauna of Scott and Seringapatam reefs, further to the north (see maps in Station and Transect data, this volume), has been somewhat better studied. Small collections were made in the 1970 s by various workers and a Russian research ship stopped at Scott Reef in 1975. They recorded 55 species of decapods from 7 families and 31 genera (Tsareva, 1980). Berry and Morgan (1986) reported 56 species collected from Scott and Seringapatam reefs during the 1984 WA Museum expedition, but the sampling effort of the study was low. In 1982 a short survey of Mermaid and Clerke reefs (Rowley Shoals) produced a small collection of decapod crustacean species, 12 species from Mermaid Reef and 38 species from Clerke Reef (unpublished data, WA Museum Crustacean Collection). Until now these records have largely remained the basis of our knowledge of the crustaceans from the Rowley Shoals.

Collection during this 2006 survey was systematic and extensive, allowing for a comparison between the three reef systems (Rowley Shoals, Scott and Seringapatam). The results of this survey represent a significant increase to the known crustacean fauna of these atolls.

\section{METHODS}

\section{Sample collection and processing}

A total of 44 stations (7 intertidal and 37 subtidal stations) across Mermaid (15), South Scott (14), North Scott (10) and Seringapatam (5) reefs were surveyed.

Subtidal habitats (lagoon and outer reef) were surveyed using either SCUBA diving or snorkelling. At each SCUBA station a 30 minute survey was conducted at two depths, $5 \mathrm{~m}$ and $12 \mathrm{~m}$ mean sea level. A $25 \mathrm{~m}$ by $1 \mathrm{~m}$ transect line was laid at each of the chosen depth contours over the dominant habitat and visual records and collections of crustaceans were made from each transect and from the surrounding area. Only one depth was sampled at two stations: South Scott Reef station 29 (depth of $13 \mathrm{~m}$ ) and Seringapatam Reef station 42 


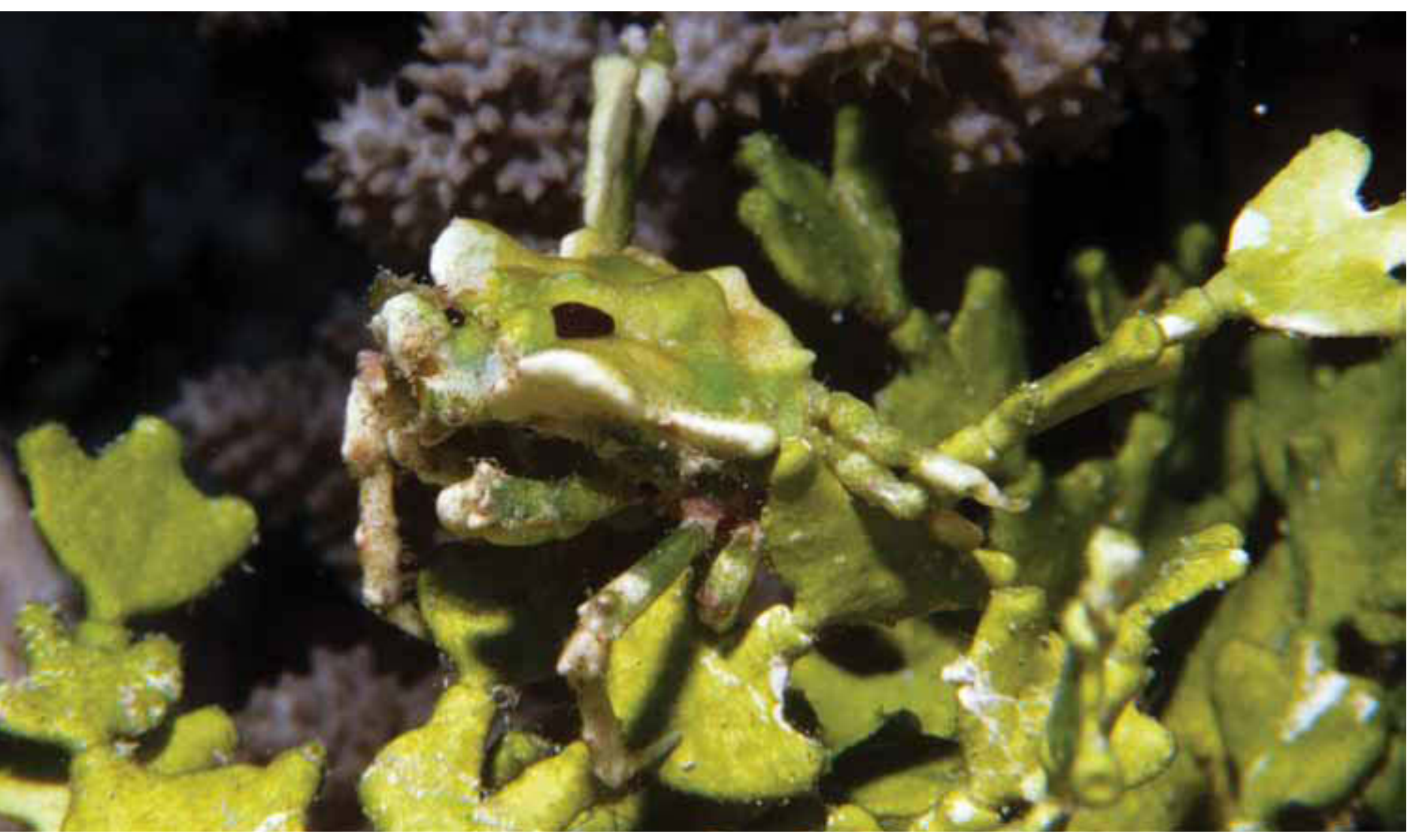

Above: The cryptic crab, Huenia brevifrons (Ward, 1941) on the algae, Halimeda. (Photo: Clay Bryce)

(depth of $7 \mathrm{~m}$ ). Both these stations were in lagoons with reduced depth profiles (bommies over sand). Qualitative sampling of the crustacean diversity was conducted at four stations by snorkel (stn 6) and drift dives (10, $13 \& 40)$.

No transect lines were laid at intertidal stations however, a 30 minute survey was conducted by shore collecting and visual records at each of the inner and outer platform zones. Sampling effort at these stations varied due to some platform stations having to be sampled at times other than low tide.

Emphasis was placed on recording species richness, which involved the examination and collection of various substrates such as live and dead coral heads, rocks, sand, sponges, echinoderms, and algae. Collected coral and rock were systematically broken down, while sponges, soft corals and ascidians were cut open to extract living crustaceans. The remaining debris was then sorted through to find all remaining crustaceans. Complex branching substrates, including algae and soft corals, were washed in a tray of sea water and clove oil to narcotise the crustaceans. Live material was euthanized by freezing and then preserved in $70 \%$ ethanol. Visual records were made only where a confident identification of species was possible.

Specimens were identified to species whenever possible using a dissecting microscope. All identifications were made where possible prior to placement into ethanol so the live colouration could be examined. Where species were not easily identified in the field they were treated at the order, infraorder or family level. The identifications of a small number of specimens were validated at the WA Museum but the majority of species have retained their field identifications. Current accepted names and systematic placement follow Davie (2002) and Ng et al., (2008). Specimens collected during the survey are housed at the WA Museum.

Given the complexity of recording very motile and cryptic crustaceans with time constraints (dive time at each station), this survey is based mainly on decapod and stomatopod crustaceans. Opportunistic collecting of isopods was undertaken but these were not included in this paper. Specimens were housed at the WA Museum and await further study.

\section{Data analysis}

Crustacean assemblages were compared among the sampled reefs (Mermaid, North Scott, South Scott, and Seringapatam reefs) and habitats (intertidal vs. subtidal, lagoon vs. outer reef slope). Data is thus arranged as a species matrix defining whole reef systems or parts of it. The degree of similarity between these chosen matrices can give insights into the relationships between reefs and the factors that may be influencing species 
distributions, such as particular microhabitats, depth and exposure at low tide.

Data was analysed using PRIMER v6.1.11 and PERMANOVA v1.0.1 based on the presence or absence of each species. Due to non-standard search effort at some stations these were omitted from subsequent data analyses. The first four stations (trialling sampling methods), drift dive stations of reef channels $(10,13 \& 40)$, the snorkel stations (6), and any opportunistic collections of species were all omitted. The resulting data matrix consisted of 138 taxa from 36 stations.

The observed species richness (Sobs) of the four shelf atolls was calculated from the dataset. Projected values of species richness were calculated using two non-parametric methods to estimate the number of species that would be collected as the number of samples approaches infinity. The Bootstrap method examines the proportion of samples containing each species, while the Jacknife method is a function of the numbers of species present in one or two samples (Clarke and Gorley, 2006).

Non-metric multidimensional scaling (nMDS) and cluster analysis were used to explore the relationships among the reefs and habitats. Similarity profiles (SIMPROF) were used to test the significance of the clusters formed (Clarke and Gorley, 2006). Similarity percentages (SIMPER, Clarke and Warwick, 2001) were used to determine which species contributed to differences among habitats and reefs. Differences between reef system groups and habitat types were further analysed using PERMANOVA (Anderson et al., 2008). All analyses used the untransformed presence/absence species data and a Bray-Curtis similarity matrix.
Three main habitat types (platform, outer reef and lagoon) were examined. As not all habitats were sampled at every reef the PERMANOVA considered habitats to be nested in reef and both reef and habitat were fixed factors. As there was uneven replication of the habitats within each reef system PERMANOVA was run using a type III (partial) model and the permutation was done on the residuals under a reduced model. The $p$ value was calculated by both permutation and Monte Carlo methods, if the number of permutations was $>25$ then the permutation $p$ values were reported, if the number of permutations was $<25$, then the Monte Carlo $\mathrm{p}$ values were used.

Differences in the assemblages at different depths were examined only for subtidal habitats, lagoon and outer reef zones. The unidentified mixed species (stomatopods, galatheids and caridean shrimps) were removed prior to analysis. As all depths and these two habitats were sampled at all reefs the PERMANOVA model considered reef, habitat and depth to be fixed orthogonal factors and used a type III (partial) model, and the permutation was done on the residuals under a reduced model.

\section{RESULTS}

\section{Species richness}

Observed species richness.

A total of 157 species were recorded from the 2006 collections, of which 87 species are new for the region (Table 1). Species richness for the individual reefs was 79 species (Mermaid Reef), 105 species (South Scott Reef), 63 species (North Scott Reef) and 40 species (Seringapatam Reef).

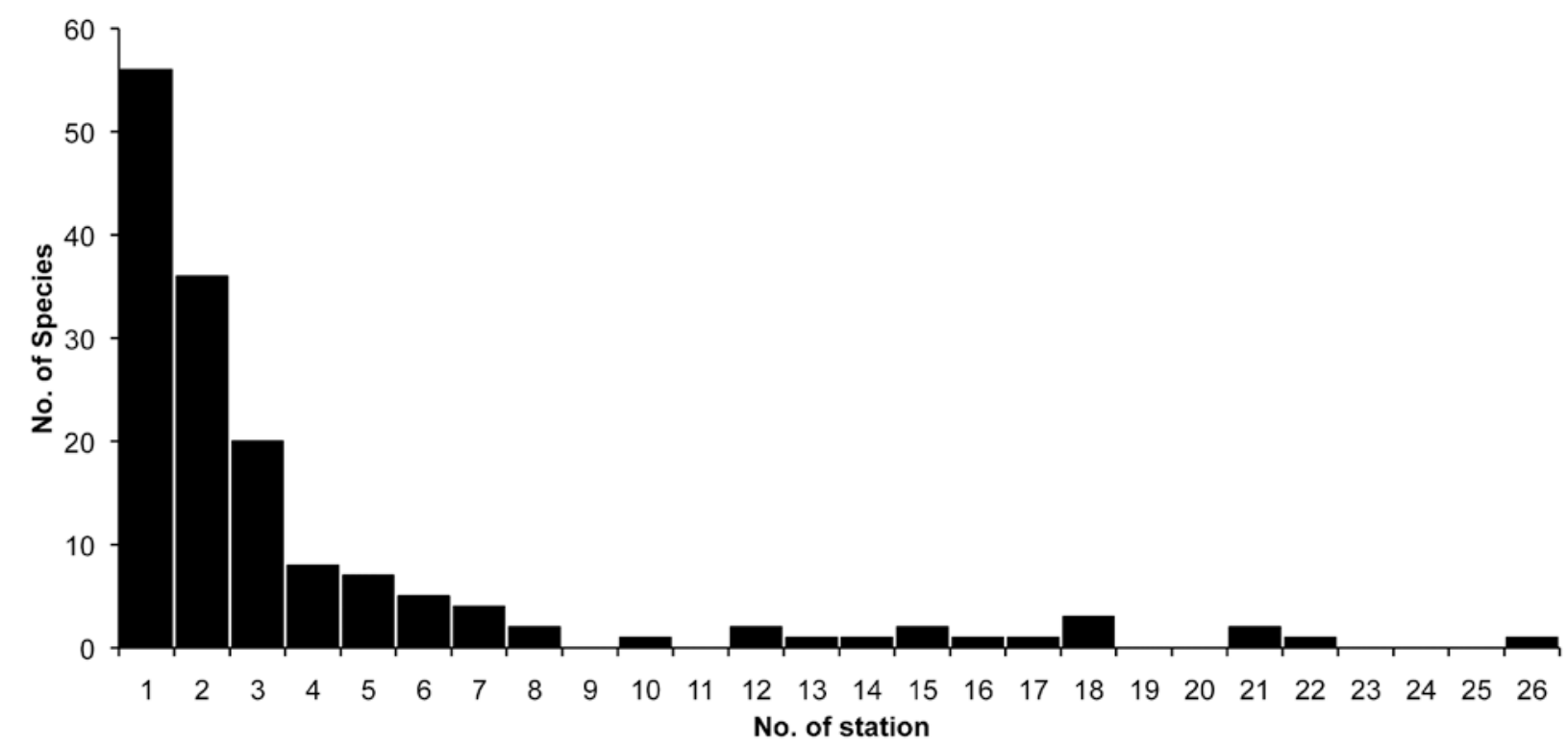

Figure 1 Frequency distribution of the number of stations at which species were recorded. 


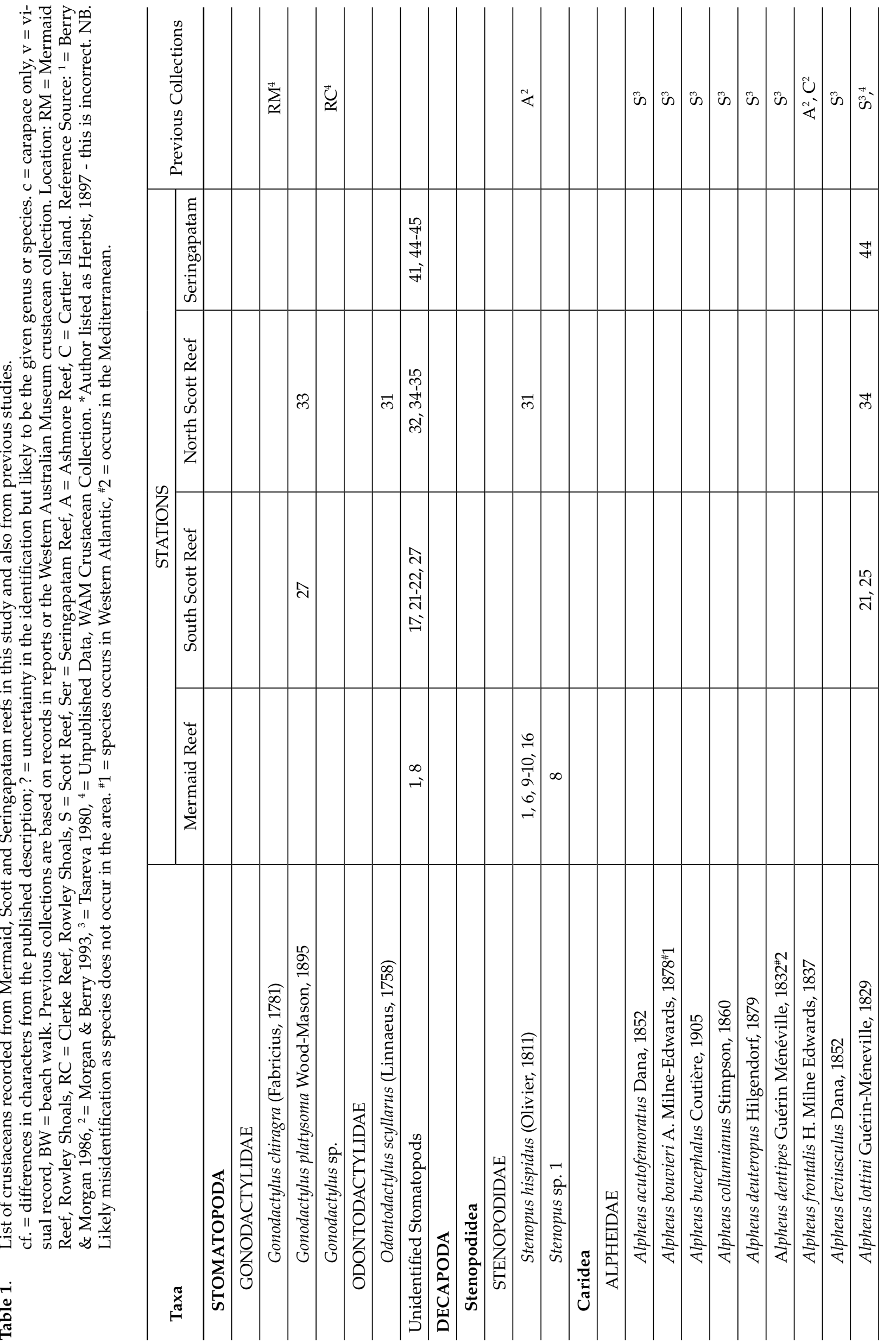




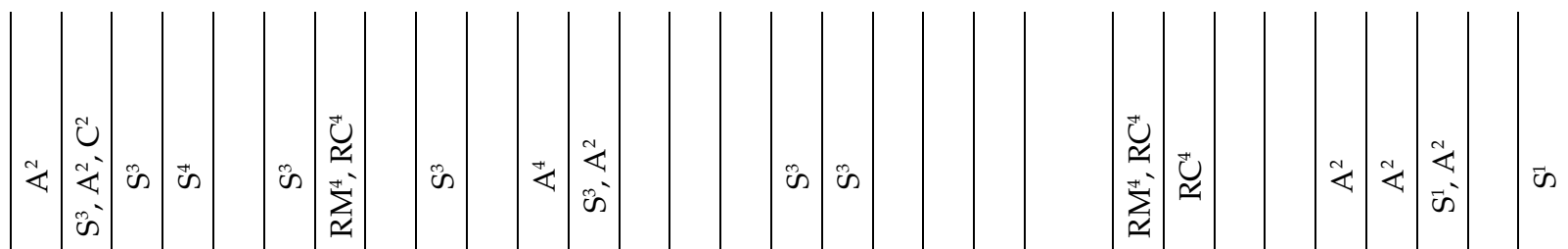

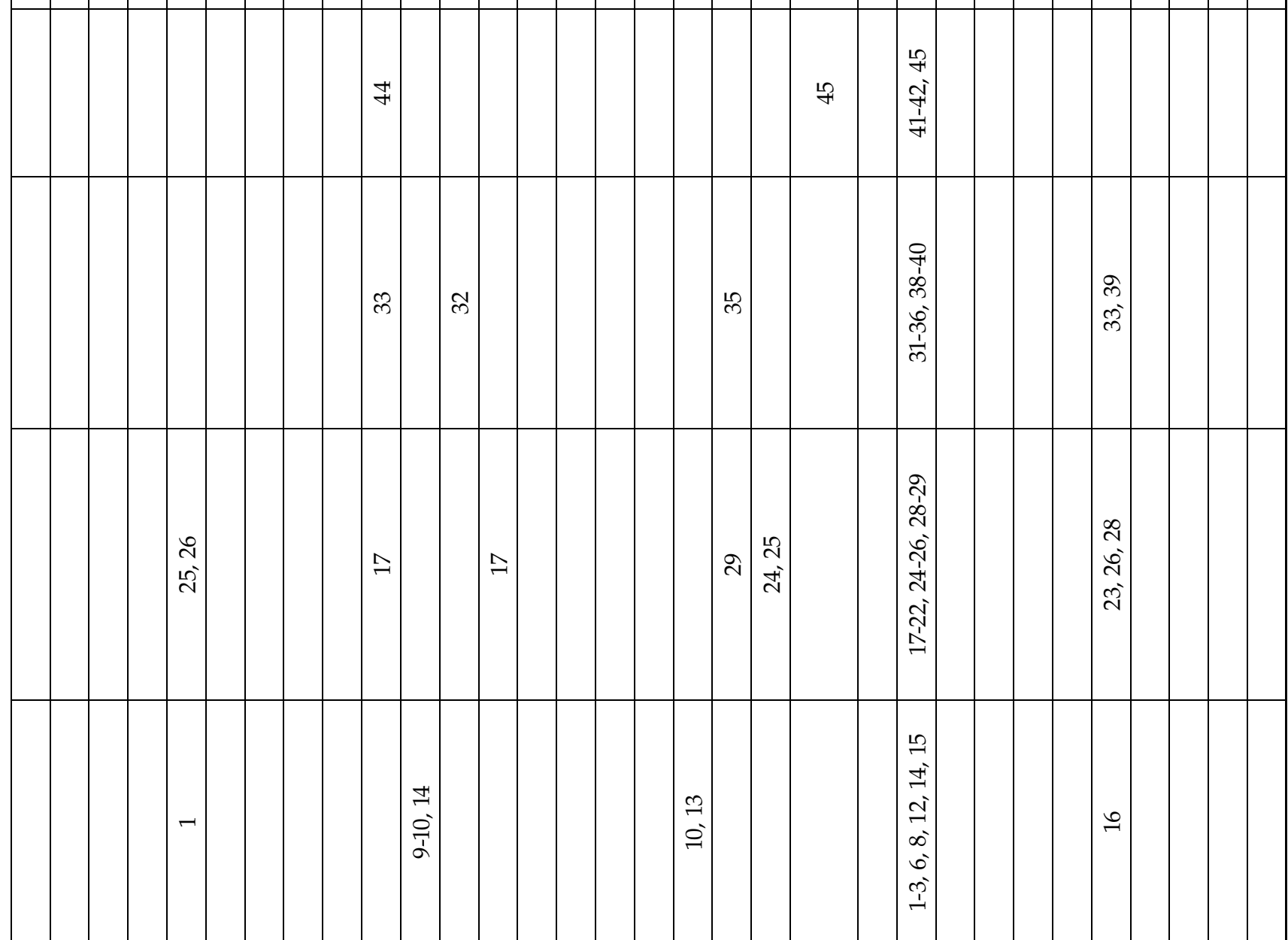

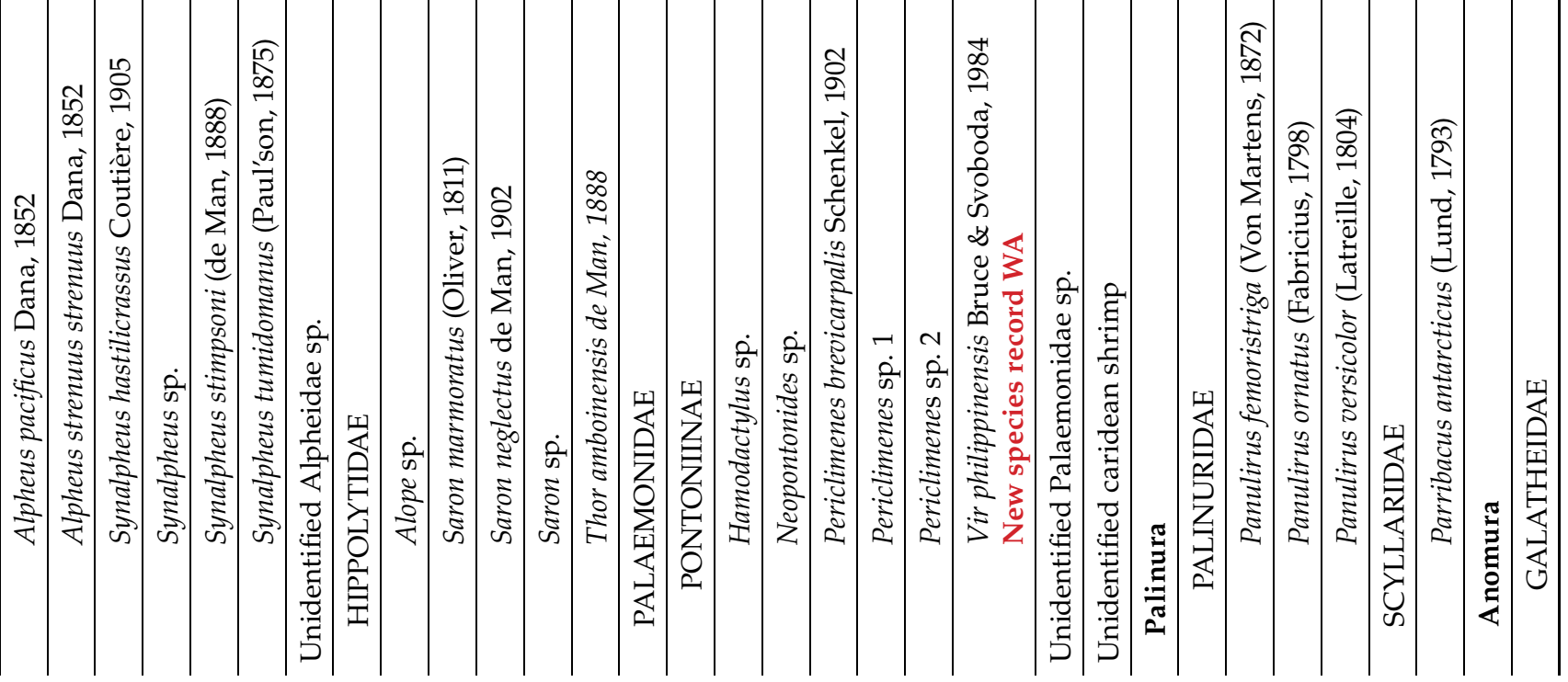




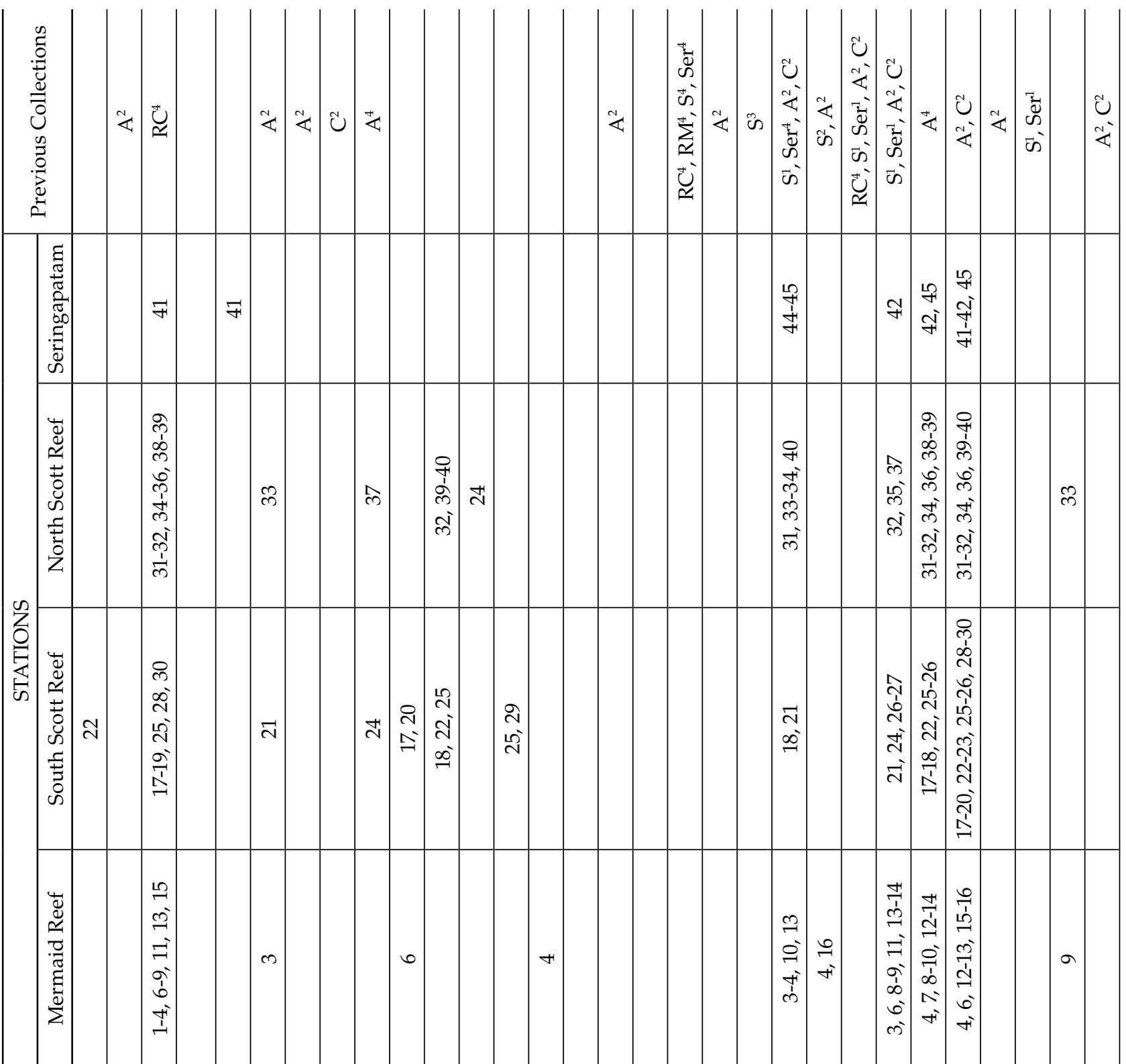

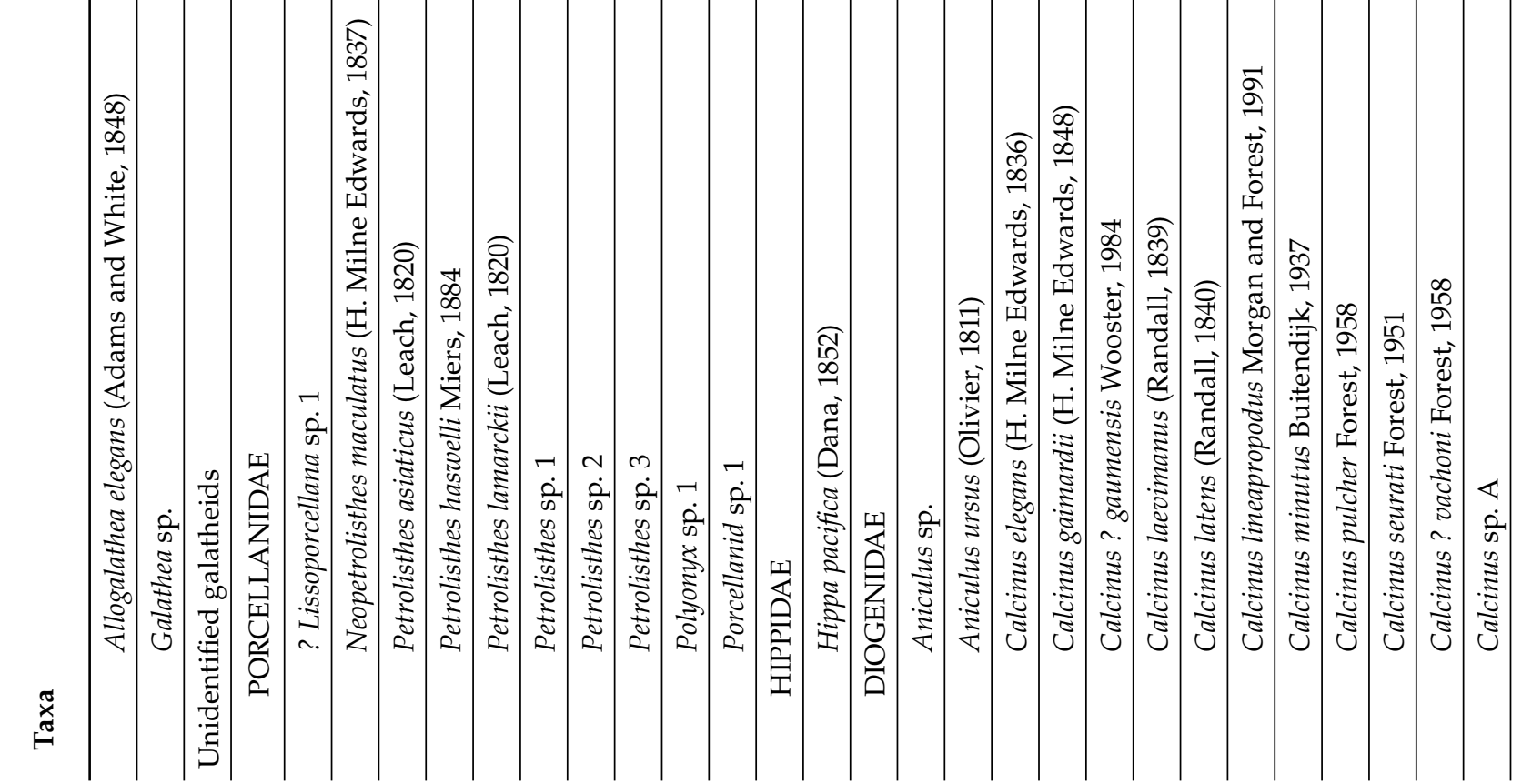




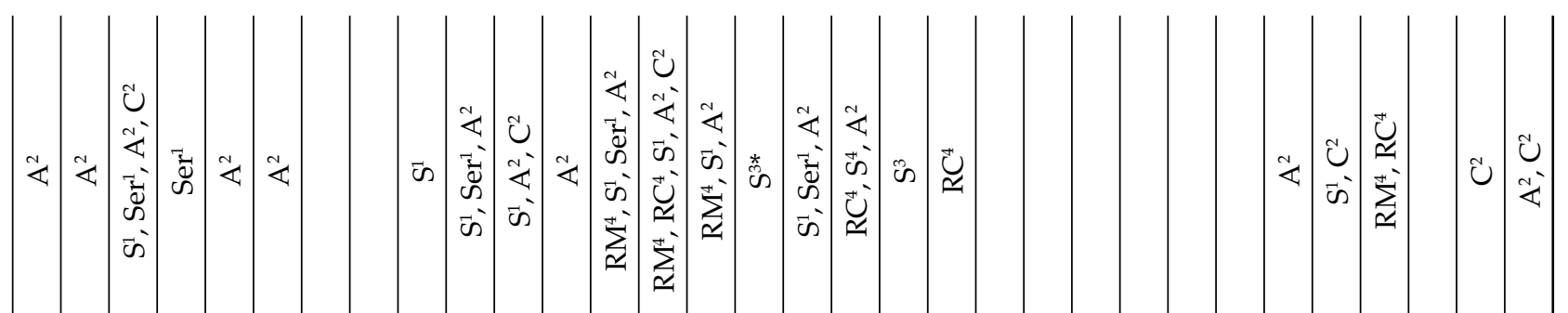

F $\quad$ F

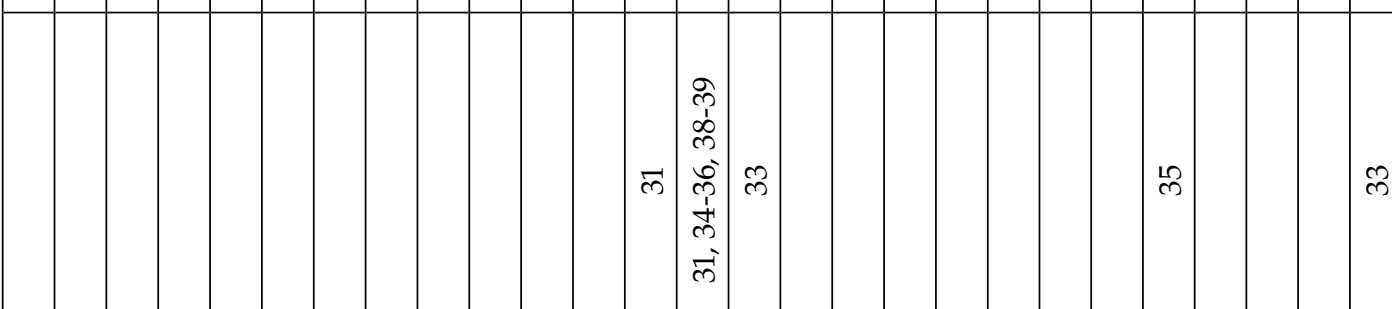

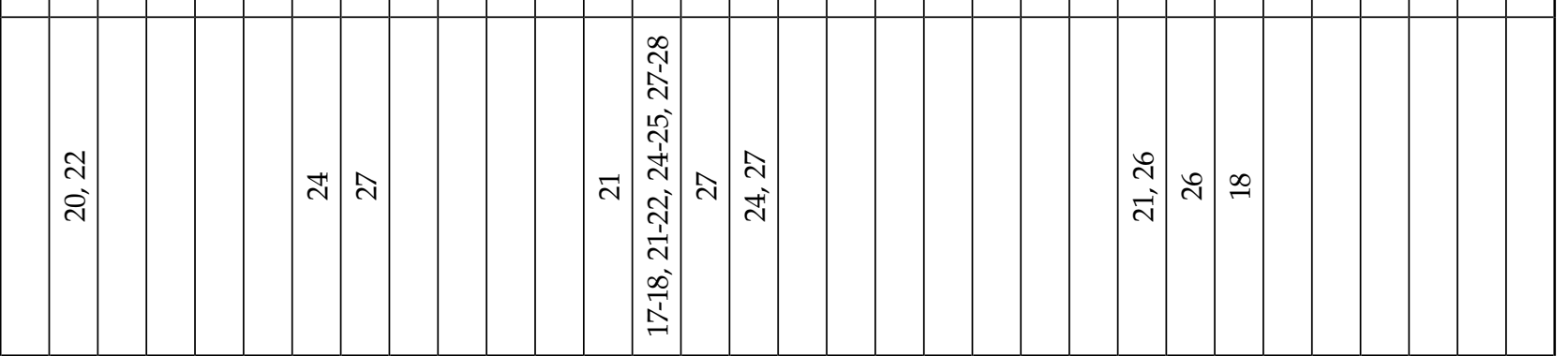

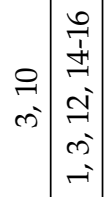

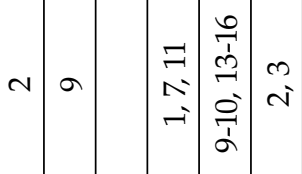

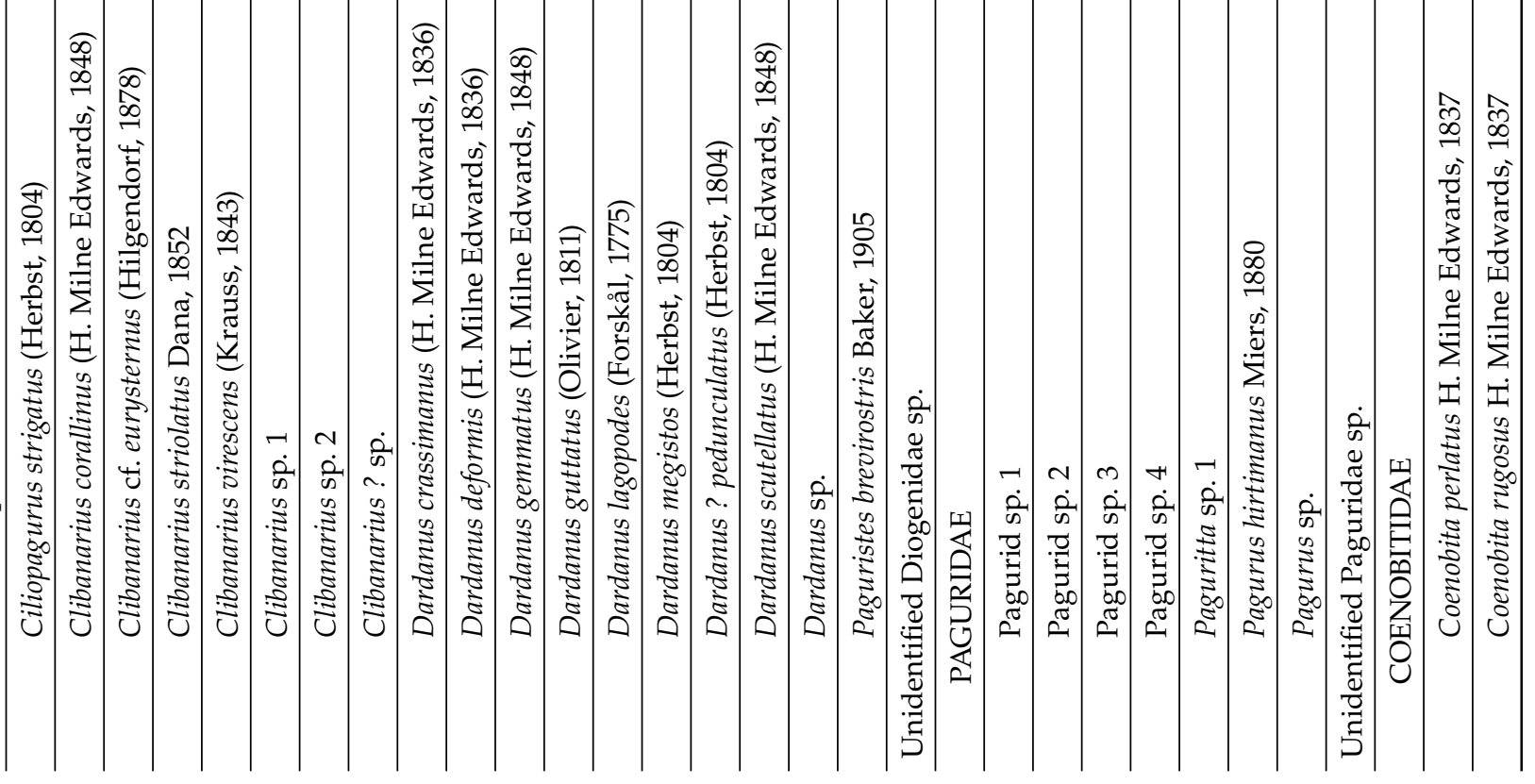



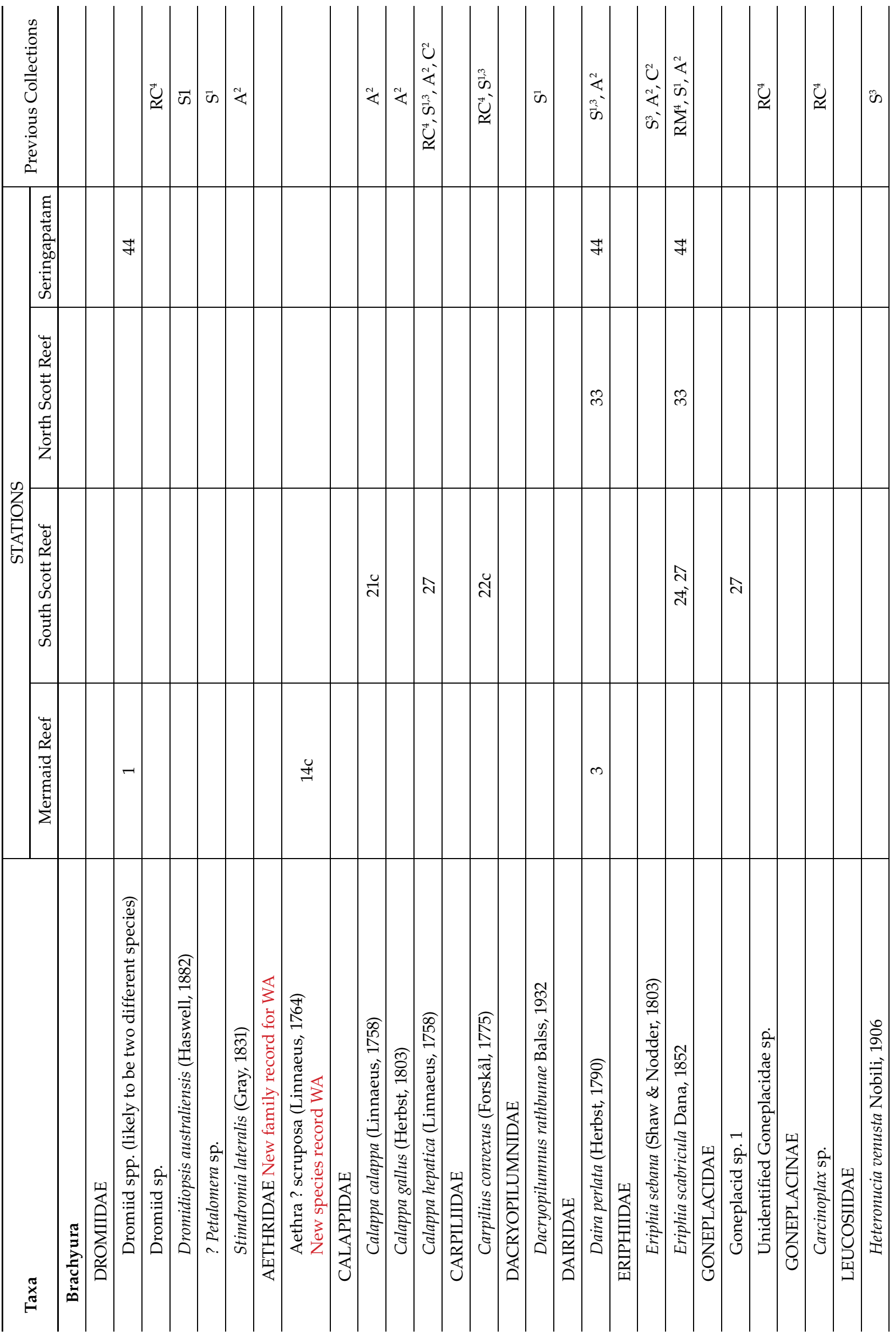


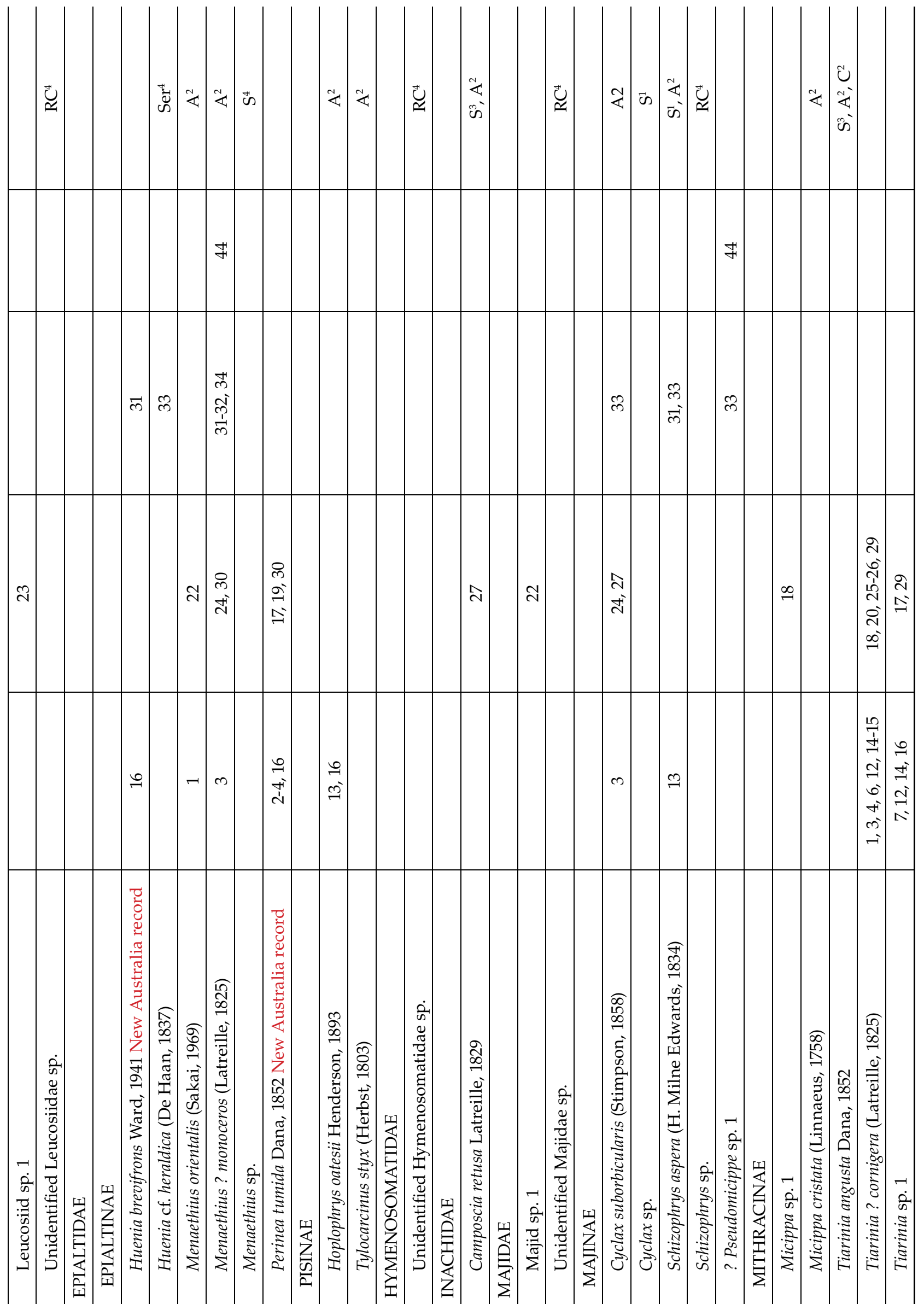




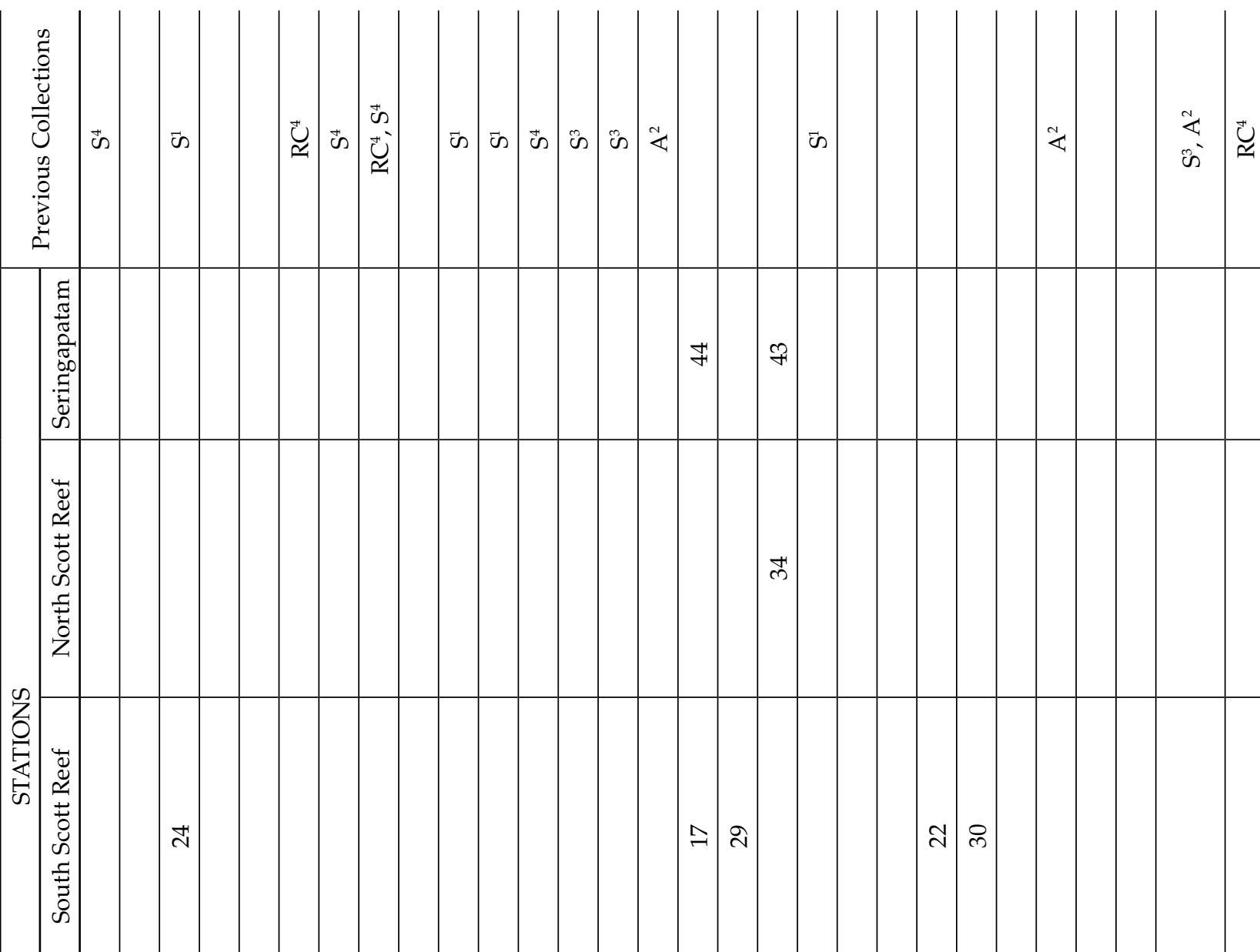

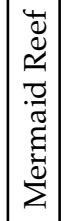

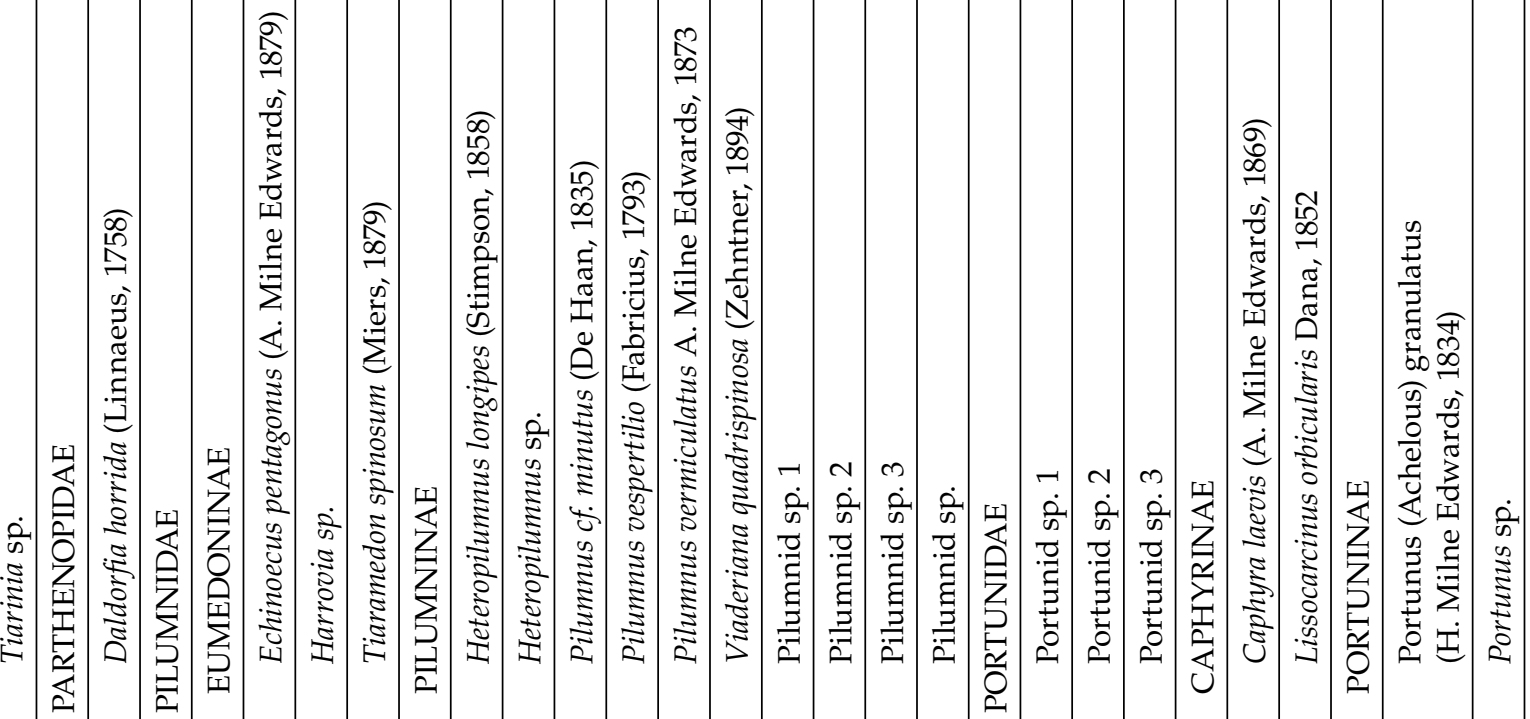




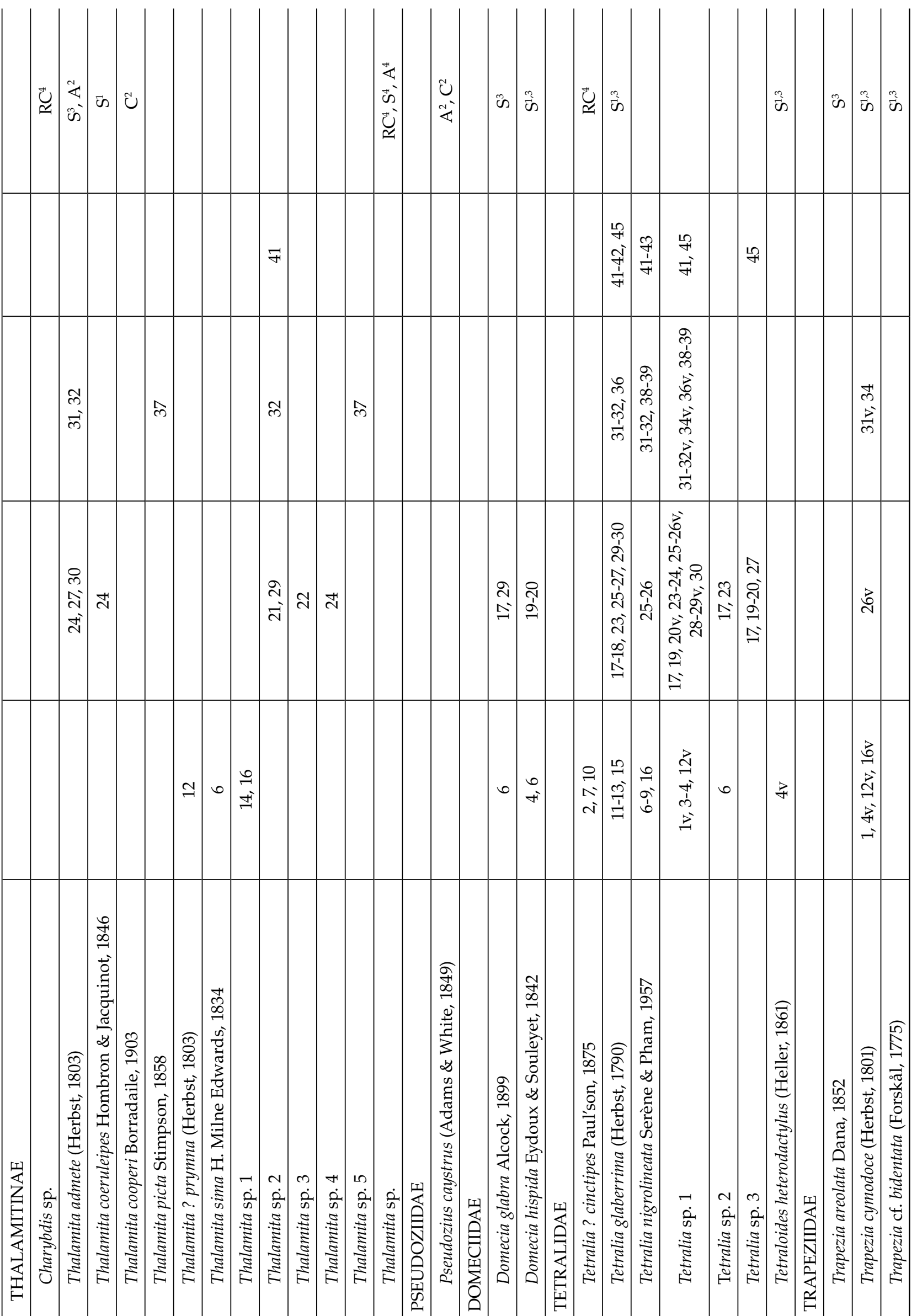




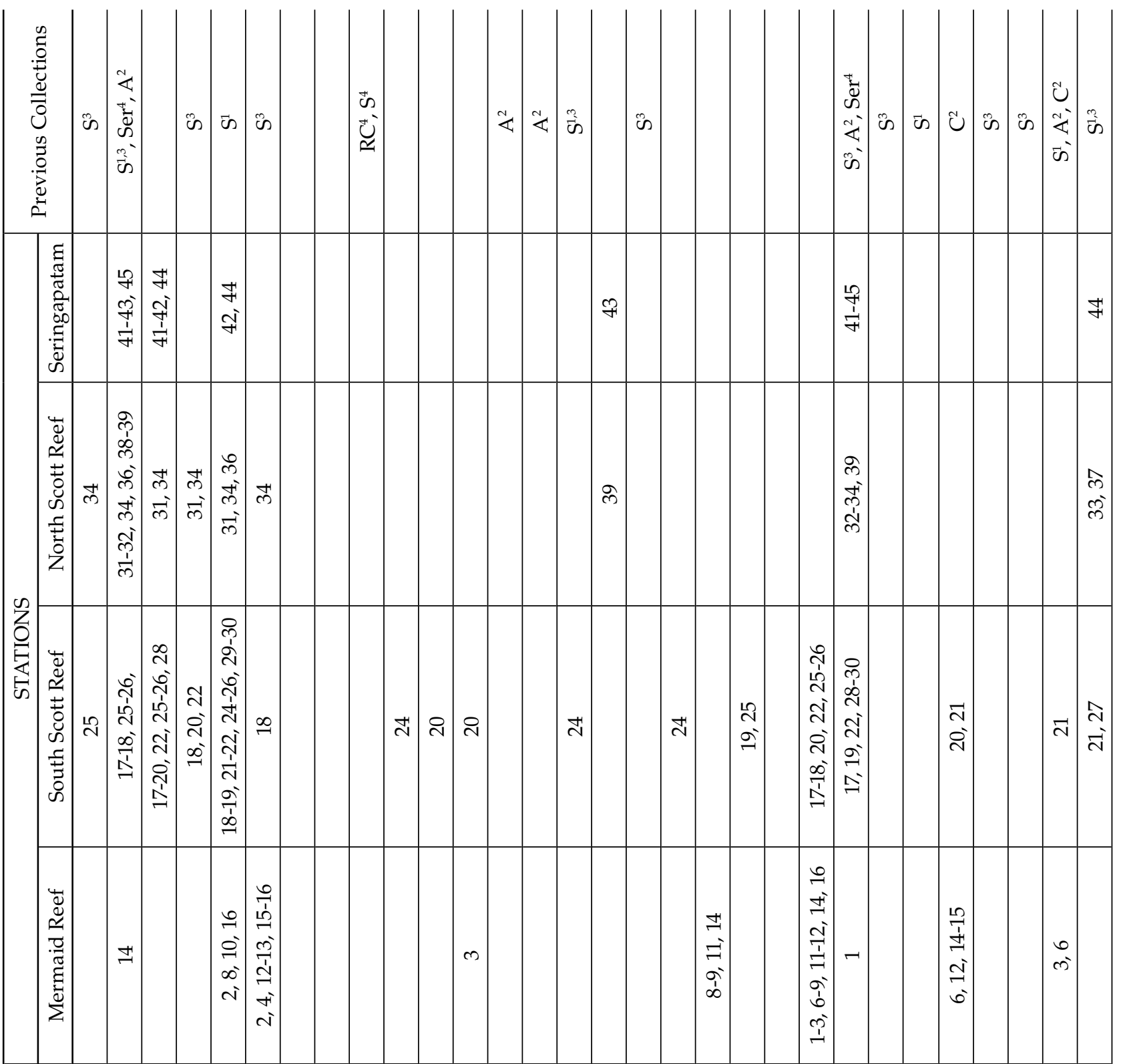

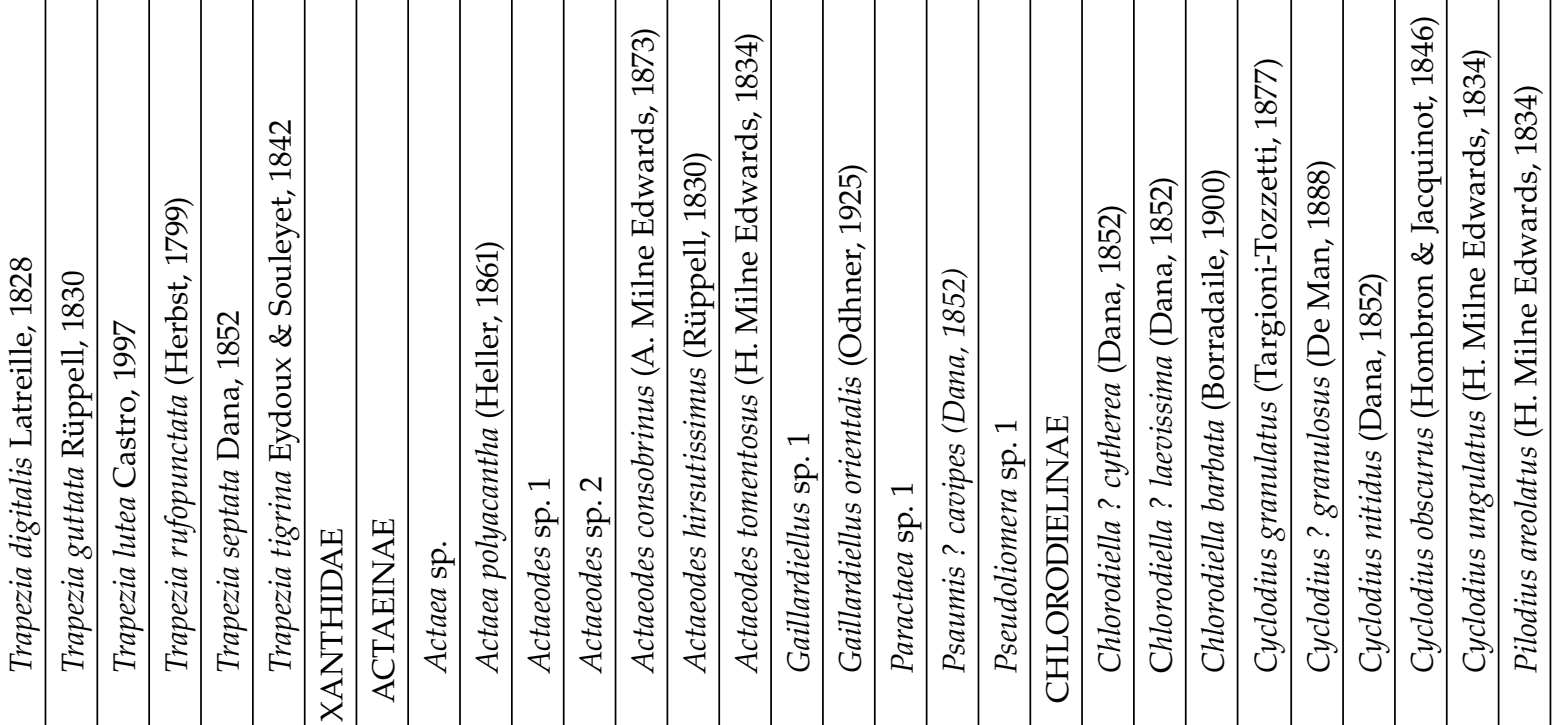




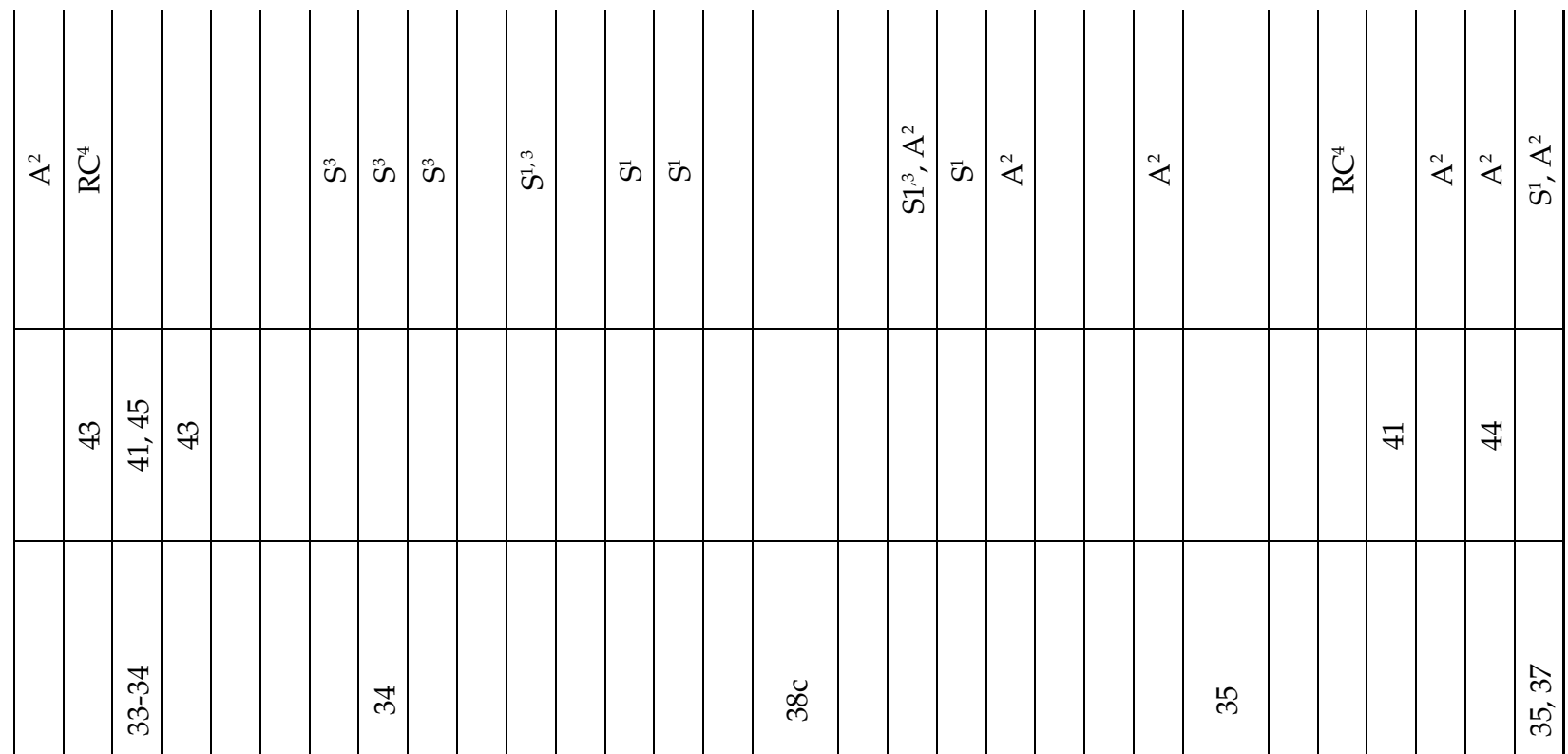

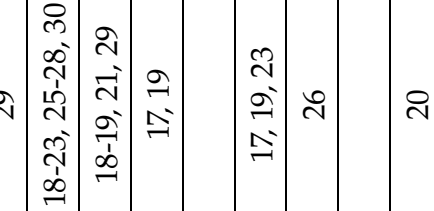

$\mathbb{N}$
$\vdots$

츤

$\therefore$

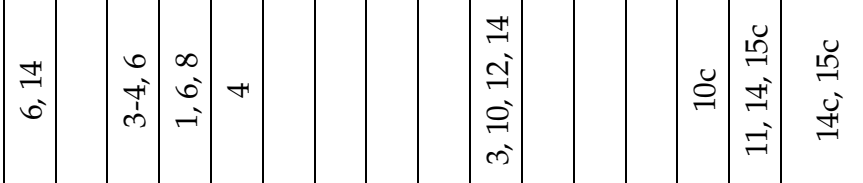

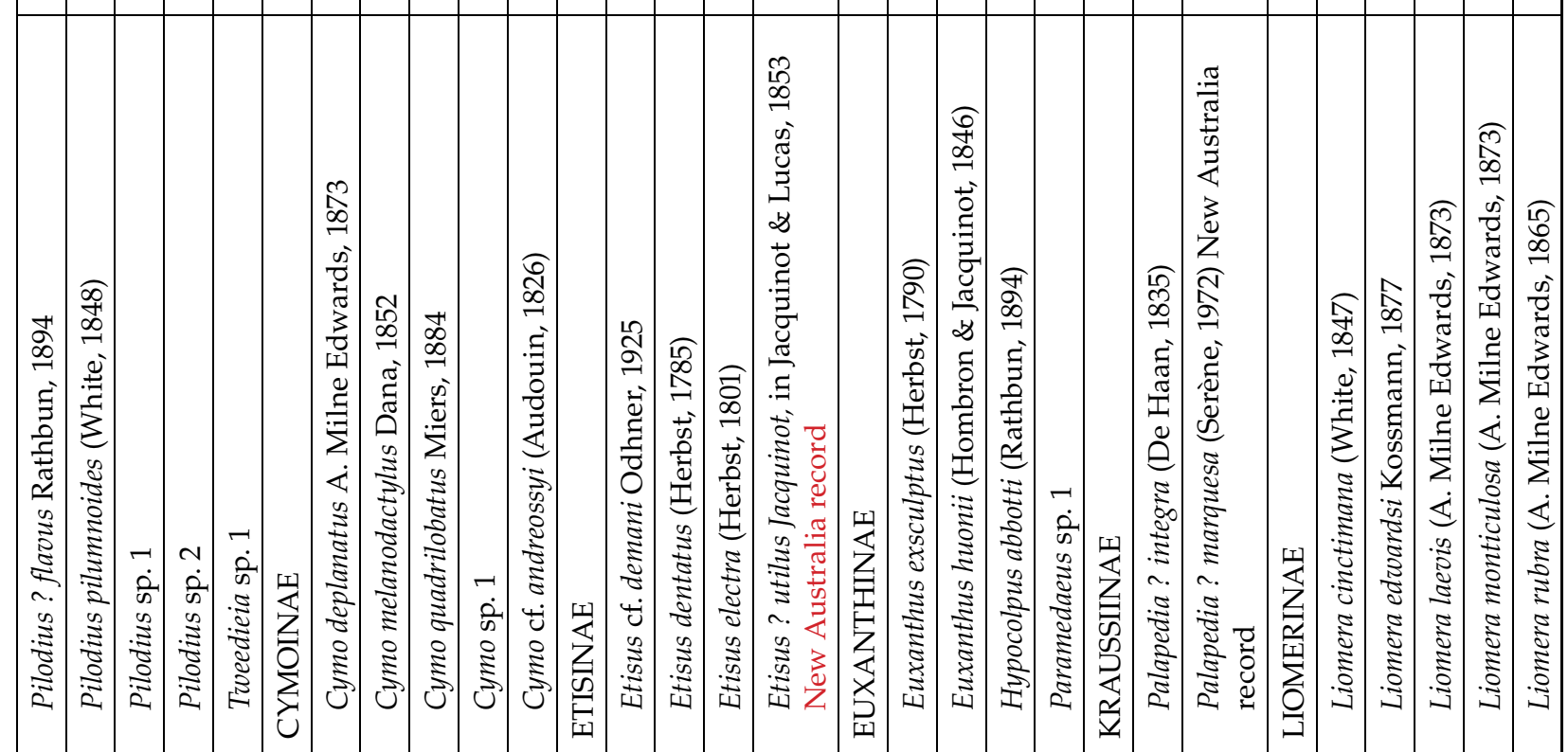




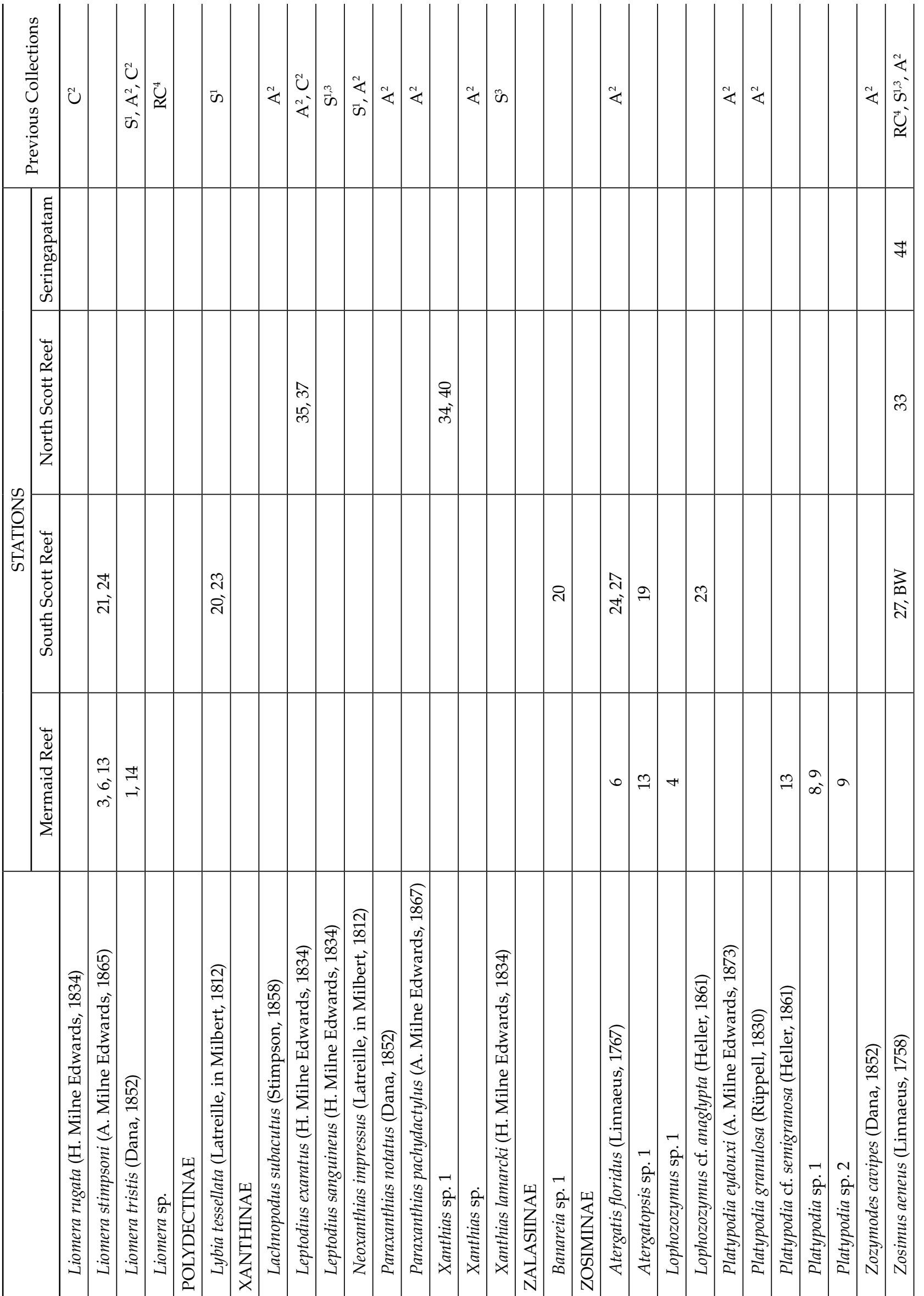




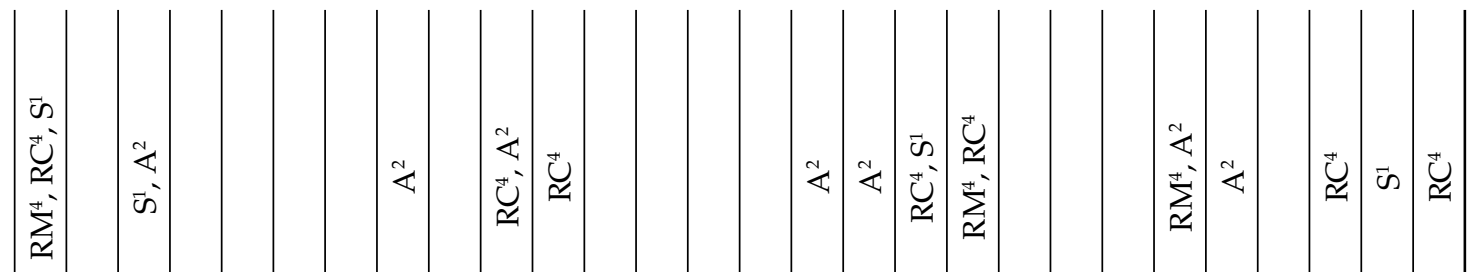

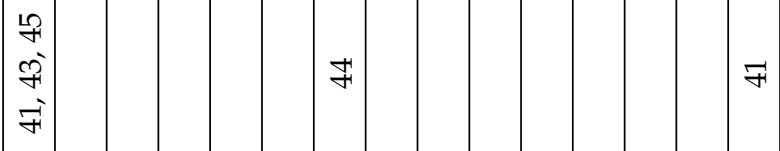

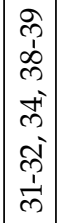

F $\quad \begin{aligned} & 0 \\ & m \\ & \infty \\ & m\end{aligned}$

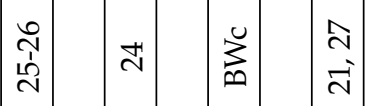

הิ
ते
ה 
Table 2 Number of crustacean species recorded from the 2006 survey compared with the cumulative number of species recorded from previous collections. Recollected Species: number of species recorded at each reef visited during the 2006 survey that were also collected by previous surveys in the region. The numbers of new records of crustaceans for each reef visited in 2006 are provided.

\begin{tabular}{l|c|c|c}
\hline & & Reef & Scott \\
Source & Mermaid & 106 & 13 \\
\hline Previous Collections & 12 & 128 & 40 \\
2006 Survey & 79 & 61 & 22 \\
Recollected Species & 34 & 67 & 18 \\
New Records & 45 & Seringapatam \\
\hline
\end{tabular}

These figures represent a more than doubling of species previously recorded from Mermaid and Seringapatam reefs and an increase in the number of species from Scott Reef (Table 2). Furthermore, the number of species will increase with identification of galatheids, caridean shrimp, stomatopods and other species that require further identification.

Two species from Mermaid Reef, 40 from Scott Reef and four from Seringapatam Reef were previously collected from each location (Table 1). These values are based on those species only having full species-level identifications. It is expected that the number of repeat collections will increase with further study of the material as several specimens in both the current and previous collections were not fully identified.

The majority of the species collected (112 species, or $73 \%$ ) were rare, only being recorded from three or less stations (Figure 1). Twenty-six species (17\%) were common, occurring at four to nine stations and 16 species $(10 \%)$ were considered widespread (10+ stations).

Unique species are defined as those that were recorded only from one reef, and are not shared with the other reefs examined. Mermaid Reef recorded the highest proportion, 31\% (24 species), of unique crustacean species, with South Scott Reef recording 29\% (29 species) (Figure 2). Proportions of unique species at North Scott and Seringapatam Reefs were 19\% (11 species) and 18\% (6 species) respectively.

\section{Estimated species richness}

The species accumulation curve of observed species (Sobs) did not reach an asymptote indicating that the sampling had not fully sampled the study area and further sampling would likely reveal more species of crustaceans (Figure 3). Projected estimates of diversity for the area, as provided by non-parametric analyses, ranged from 157 (Bootstrap) to 197 species (Jacknife 1). Neither estimator reached an asymptote. They therefore represent minimum estimates of species richness using these methods.

\section{Species richness within families}

Twenty eight decapod families are represented in

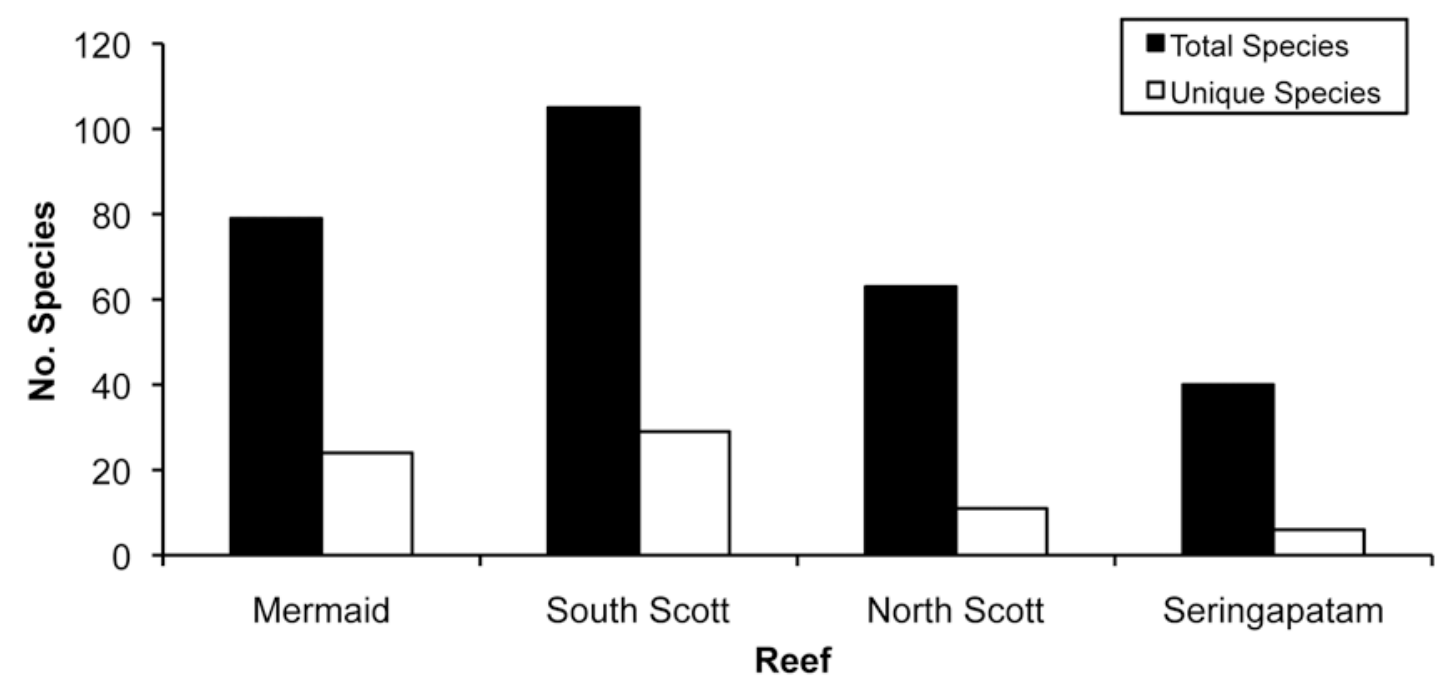

Figure 2 Total number of species and the number of unique species (not shared with other reefs) recorded at Mermaid, South Scott, North Scott and Seringapatam reefs during the September 2006 survey. 

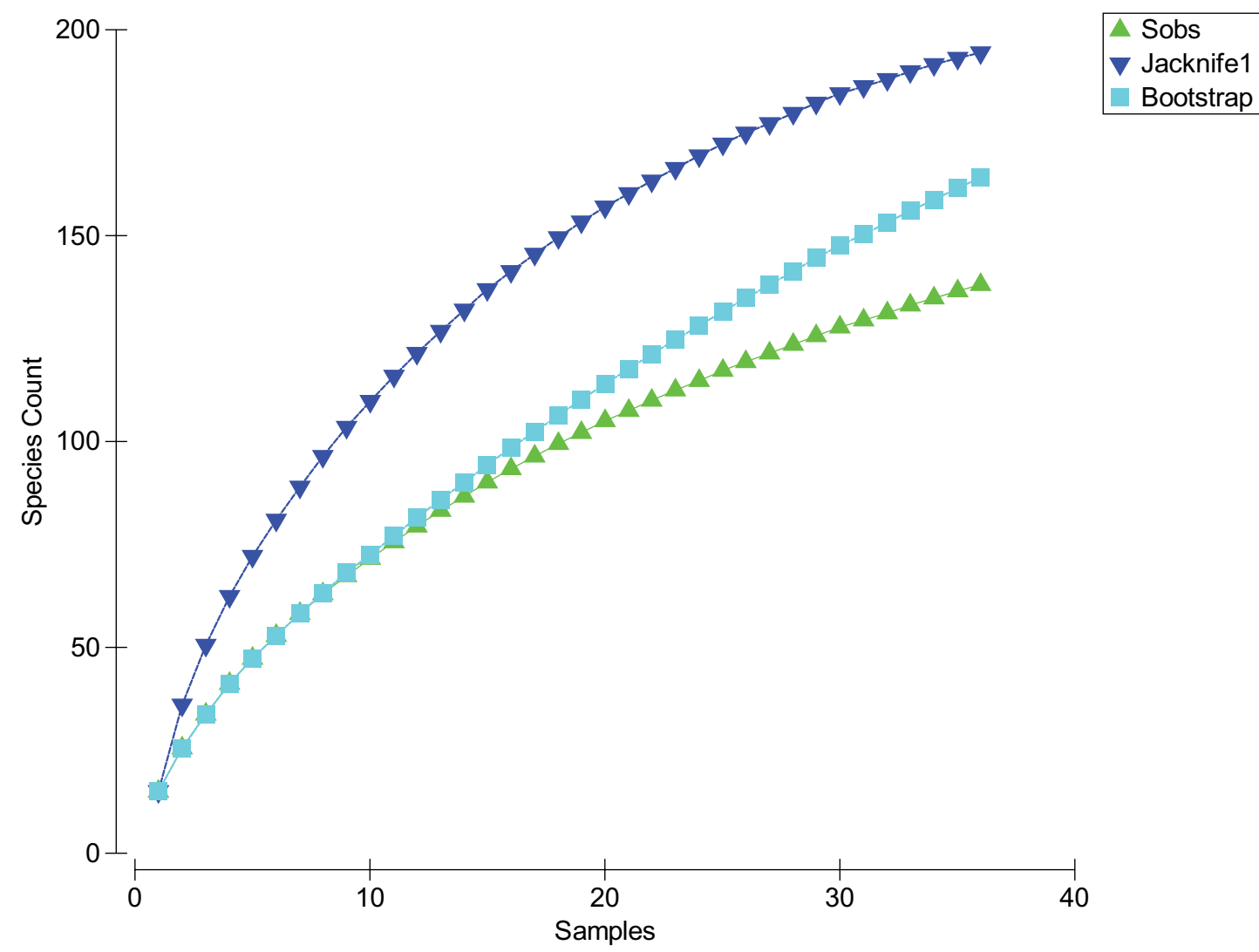

Figure 3 Species accumulation curve of the species observed (Sobs) for 36 stations at Mermaid, Scott and Seringapatam reefs, and projected estimates of diversity based on Bootstrap and Jacknife non-parametric methods.

the 2006 collections. Caridean shrimp families and the family Galatheidae have been omitted due to their identifications being incomplete.

Species richness within families across the reefs ranged from one species (Palinuridae, Dromiidae, Leucosiidae, Aethridae, Dairidae, Daldorphiidae, Carpiliidae, Eriphiidae, Goneplacidae, Cryptochiridae) to a maximum of 45 species (Xanthidae) (Table 3). Seventeen families were represented by three or fewer species. Four families had between four and ten species Paguridae (6), Porcellanidae (8), Trapeziidae (8) and Tetralidae (7). Four families had more than 10 species each, Xanthidae (45 species), Majidae (14), Diogenidae (14) and Portunidae (14), (Table 3).

The Xanthidae was the most diverse family at all reefs and had the greatest observed change in species richness across reefs: Mermaid (23 species), South Scott (29), North Scott (11) and Seringapatam (9). Diversity of the coral inhabiting crabs (Trapeziidae and Tetralidae) was relatively consistent across the reefs with a maximum of 12 species being recorded at South Scott and a minimum of seven species at Seringapatam Reef, and 10 species at both Mermaid and North Scott reefs. A similar pattern was observed in the anomuran family Diogenidae: South Scott Reef (max. 11), Seringapatam Reef (min. 6), Mermaid and
North Scott Reefs (8 each). Diversity of the Majidae across the reefs is highest at Mermaid and South Scott reefs (9), and lowest at Seringapatam Reef (2).

The ordering of families based on species richness should not be treated as conclusive because the identifications of galatheids and caridean shrimps has yet to be completed. Both of these decapod groups were observed to be significant components of the faunas at all reefs, in particular galatheids. Despite the unavailability of this data it is unlikely either family would surpass the observed diversity of the Xanthidae at any of the reefs.

\section{Site diversity}

Species richness at sites ranged from a minimum of six species (Mermaid stn 7) to a maximum of 25 species (South Scott stn 24). Mean site richness within reef systems was highest at South Scott Reef (16.5 species), followed in decreasing order of richness by Mermaid (12.4), Seringapatam (11.8) and North Scott reefs (10.7) (Table 4). The reef platform stations showed the highest species richness (average of 17.2 species), and lagoon stations had the lowest (11.8). Outer reef stations had an average number of 13.7 species. The average across habitats was 13.5 species. 


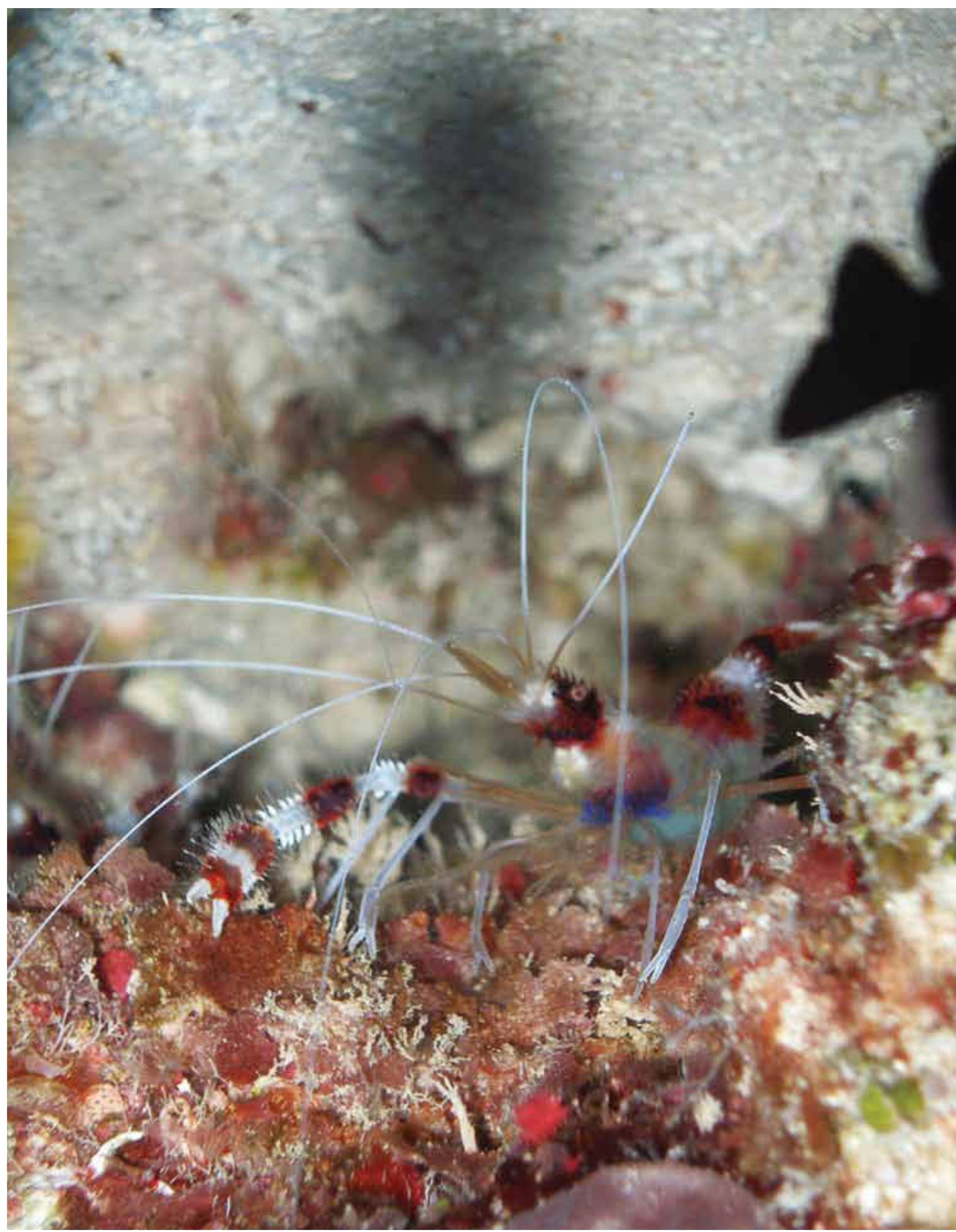

Above: The cleaner shrimp, Stenopus hispidus (Olivier, 1811) was common under ledges. (Photo: Sue Morrison) 
Table 3 Species richness within decapod families across all reefs and within each reef. Caridean shrimps and galatheids have been omitted due to the incomplete identifications among these groups. The four most species rich families are highlighted, the highest ranked in orange and the others in grey.

\begin{tabular}{|c|c|c|c|c|c|}
\hline \multirow[t]{2}{*}{ Family } & \multicolumn{5}{|c|}{ Number of Species } \\
\hline & All Reefs & Mermaid & Sth Scott & Nth Scott & Seringapatam \\
\hline \multicolumn{6}{|l|}{ Stenopodidea } \\
\hline STENOPODIDAE & 2 & 2 & 0 & 1 & 0 \\
\hline \multicolumn{6}{|l|}{ Palinura } \\
\hline PALINURIDAE & 1 & 1 & 1 & 1 & 0 \\
\hline \multicolumn{6}{|l|}{ Anomura } \\
\hline DIOGENIDAE & 14 & 8 & 11 & 8 & 6 \\
\hline PAGURIDAE & 6 & 5 & 3 & 2 & 0 \\
\hline PORCELLANIDAE & 8 & 3 & 6 & 3 & 1 \\
\hline \multicolumn{6}{|l|}{ Brachyura } \\
\hline DROMIIDAE & 1 & 1 & 0 & 0 & 1 \\
\hline CALAPPIDAE & 2 & 0 & 2 & 0 & 0 \\
\hline LEUCOSIIDAE & 1 & 0 & 1 & 0 & 0 \\
\hline MAJIDAE & 14 & 9 & 9 & 6 & 2 \\
\hline AETHRIDAE & 1 & 1 & 0 & 0 & 0 \\
\hline DAIRIDAE & 1 & 1 & & 1 & 1 \\
\hline DALDORPHIIDAE & 1 & 0 & 1 & 0 & 0 \\
\hline PORTUNIDAE & 14 & 5 & 7 & 4 & 1 \\
\hline XANTHIDAE & 45 & 23 & 29 & 11 & 9 \\
\hline TETRALIDAE & 7 & 6 & 5 & 3 & 4 \\
\hline TRAPEZIIDAE & 8 & 4 & 7 & 7 & 3 \\
\hline DOMECIIDAE & 2 & 2 & 2 & 0 & 0 \\
\hline CARPILIIDAE & 1 & 0 & 1 & 0 & 0 \\
\hline PILUMNIDAE & 3 & 1 & 2 & 1 & 1 \\
\hline ERIPHIIDAE & 1 & 0 & 1 & 1 & 0 \\
\hline GONEPLACIDAE & 1 & 0 & 1 & 0 & 0 \\
\hline OCYPODIDAE & 2 & 0 & 2 & 0 & 0 \\
\hline GRAPSIDAE & 3 & 1 & 3 & 1 & 1 \\
\hline PLAGUSIIDAE & 3 & 0 & 0 & 2 & 1 \\
\hline CRYPTOCHIRIDAE & 1 & & 1 & 1 & 1 \\
\hline
\end{tabular}


Table 4 Average species richness within each reef, across reefs, and for each habitat type within and across reefs. Calculations do not include channel stations.

\begin{tabular}{|c|c|c|}
\hline Mermaid Reef & Mean & Std Dev \\
\hline Station Richness (all collections) & 12.4 & 4.03 \\
\hline Station Richness (transect only) & 10.6 & 3.58 \\
\hline Lagoon & 11.9 & 4.52 \\
\hline Outer Reef & 12 & 3.46 \\
\hline Platforms & 19 & \\
\hline \multicolumn{3}{|l|}{ South Scott Reef } \\
\hline Station Richness (all collections) & 16.5 & 4.99 \\
\hline Station Richness (transect only) & 15.8 & 4.39 \\
\hline Lagoon & 16.2 & 4.27 \\
\hline Outer Reef & 14.3 & 5.12 \\
\hline Platforms & 21.3 & 3.21 \\
\hline \multicolumn{3}{|l|}{ North Scott Reef } \\
\hline Station Richness (all collections) & 10.7 & 6.07 \\
\hline Station Richness (transect only) & 11.6 & 5.13 \\
\hline Lagoon & 10.6 & 3.51 \\
\hline Outer Reef & 16 & 7.81 \\
\hline Platforms & 11.7 & 6.43 \\
\hline \multicolumn{3}{|l|}{ Seringapatam Reef } \\
\hline Station Richness (all collections) & 11.8 & 3.7 \\
\hline Station Richness (transect only) & 11.6 & 3.97 \\
\hline Lagoon & 8.5 & 1.41 \\
\hline Outer Reef & 12.5 & 2.12 \\
\hline Platforms & 17 & \\
\hline \multicolumn{3}{|l|}{ Species Richness Across Reefs } \\
\hline All Habitats & 13.5 & 5.1 \\
\hline Lagoon & 11.8 & 4.57 \\
\hline Outer Reef & 13.7 & 4.83 \\
\hline Platforms & 17.25 & 5.96 \\
\hline
\end{tabular}


a)

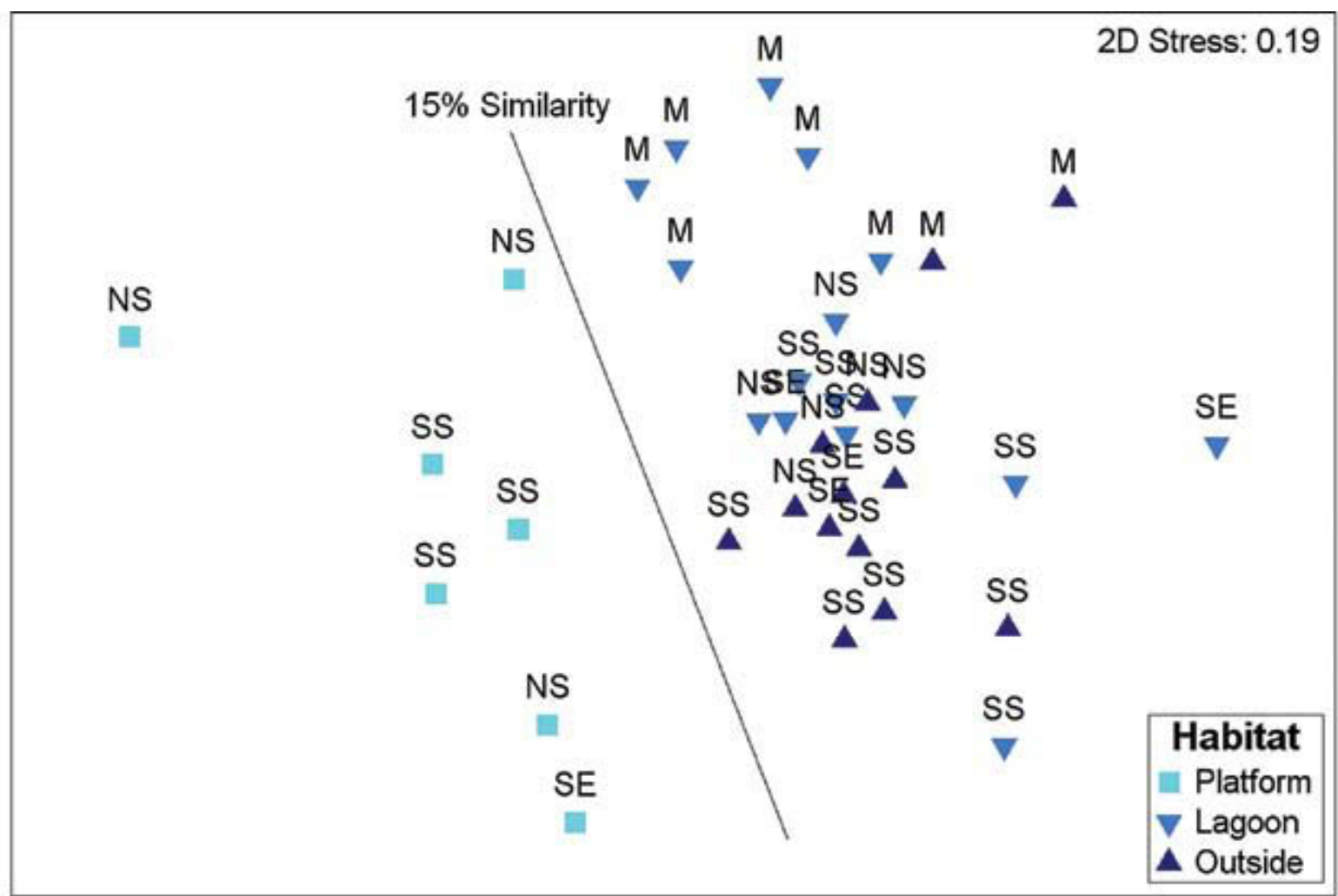

b)

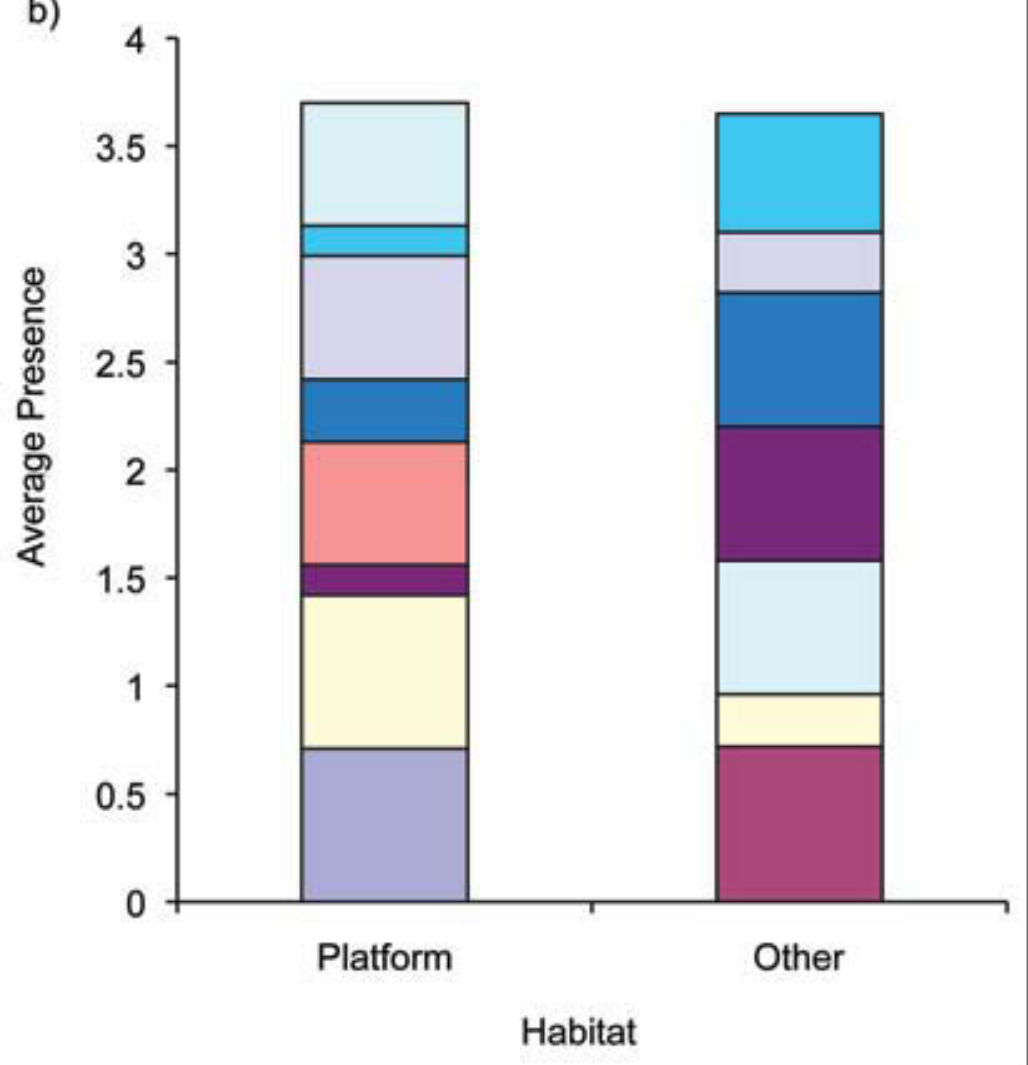

口Eriphia scabricula

$\square$ Tetralia glaberrima

口Stomatopods (unidentified)

- Galatheids (unidentified)

口Pachygrapsus sp. 1

- Tetralia sp. 1

$\square$ Calcinus lineapropodus

$\square$ Calcinus latens

$\square$ Calcinus minutus

口 Pilodius areolatus

Figure 4 Crustacean taxa from north-west Australian reefs, a) two-dimensional ordination, showing the main habitat types for each reef system, b) discriminating taxa based on average presence or absence across stations within each habitat grouping (SIMPER, Diss/SD >1). M: Mermaid, SS: South Scott, NS: North Scott, and SE: Seringapatam. The main groupings are significant at $15 \%$ similarity (SIMPROF, $\mathrm{p}<0.05$ ), Other includes the two subtidal habitats (lagoon and outer reef). 
Table 5 PERMANOVA results for the three main habitats (platform, outer reef, lagoon), a) main test, b) pairwise tests, Mermaid and South Scott reefs, $p$ value derived from the permutation method, North Scott and Seringapatam reefs, $\mathrm{p}$ value from the Monte Carlo method.

a) main test

\begin{tabular}{lccccc}
\hline Source & df & SS & MS & Pseudo-F & P(perm) \\
\hline Reef & 3 & 16575 & 5525.1 & 2.975 & 0.001 \\
Habitat(Reef) & 7 & 32424 & 4632 & 2.494 & 0.001 \\
Res & 25 & 46438 & 1857.5 & & \\
\hline Total & $\mathbf{3 5}$ & $\mathbf{9 8 4 8 8}$ & & & \\
\hline
\end{tabular}

b) pairwise tests

\begin{tabular}{lcc}
\hline Groups & $\mathbf{t}$ & $\mathbf{P}$ \\
\hline Mermaid Reef & & \\
\hline Lagoon, Outside & 1.465 & 0.034 \\
\hline & & \\
\hline South Scott Reef & & \\
\hline Lagoon, Outside & 1.185 & 0.119 \\
Lagoon, Platform & 1.784 & 0.017 \\
Outside, Platform & 1.917 & 0.015 \\
\hline & & \\
\hline North Scott Reef & & \\
\hline Lagoon, Outside & 1.368 & 0.199 \\
Lagoon, Platform & 1.879 & 0.054 \\
Outside, Platform & 1.824 & 0.046 \\
\hline & & \\
\hline Seringapatam & & \\
\hline Lagoon, Outside & 1.188 & 0.328 \\
Lagoon, Platform & 1.403 & 0.334 \\
Outside, Platform & 2.458 & 0.167 \\
\hline
\end{tabular}

Pachygrapsus sp. 1 only occurred in the platform habitats and were absent from lagoons and outer reef habitats. This is expected, as the former two species, and members of the genus Pachygrapsus, are known inhabitants of the intertidal zone, and only $P$. areolatus is also reported from the shallow subtidal. Coral associated species were either absent (Calcinus minutes and Calcinus lineapropodus, Diogenidae), or of decreased influence (Tetralia glaberrima and Tetralia sp. 1), on station similarity of platform stations. Other species, stomatopods (unidentified), and Calcinus latens, were more common in this habitat than either lagoon or outer reef habitats. Stomatopods and galatheids were not identified to species and it is likely that different species occur in the different habitats.

The PERMANOVA results support the above results with habitats nested in reefs being significantly different from each other (Table 5, $\mathrm{p}<0.05$ ). Pairwise comparisons clearly indicate separation of the platform communities from the other two habitats at South Scott Reef. Differences between lagoon and outer reef habitats were only significant within Mermaid Reef, a separation also evident in the two-dimensional ordination. No significant difference $(p>0.05)$ was observed between habitats at North Scott and Seringapatam reefs, a result of the low number of stations sampled at these reefs. The highest $p$ values are recorded for pairwise tests for Seringapatam, which had the lowest number of stations sampled (5 stations).

There is some indication that that there are differences in the platform crustacean assemblages across the three reefs where these were sampled, with the South Scott stations grouping together and one of the North Scott stations closer to the Seringapatam station. The North Scott stations were all widely separated from each other, possibly due to the low number of species collected at each station. However, there were no significant groupings of the platform stations below $15 \%$ similarity.

\section{Depths differences for the outer reef and lagoon habitats}

There were no major differences in crustacean assemblages as a result of the depth sampled at the subtidal stations, encompassing the lagoon and outer reef habitats (Figure 5a). In general, crustaceans from the shallow and deep sampling at the same station were very close on the MDS plot, and species that occurred at $5 \mathrm{~m}$ were just as likely to be collected at the $12 \mathrm{~m}$ depth. There was some evidence of the grouping of stations due to habitat and reef location (Figure $5 b$ and $c$ ). The reef 
a)

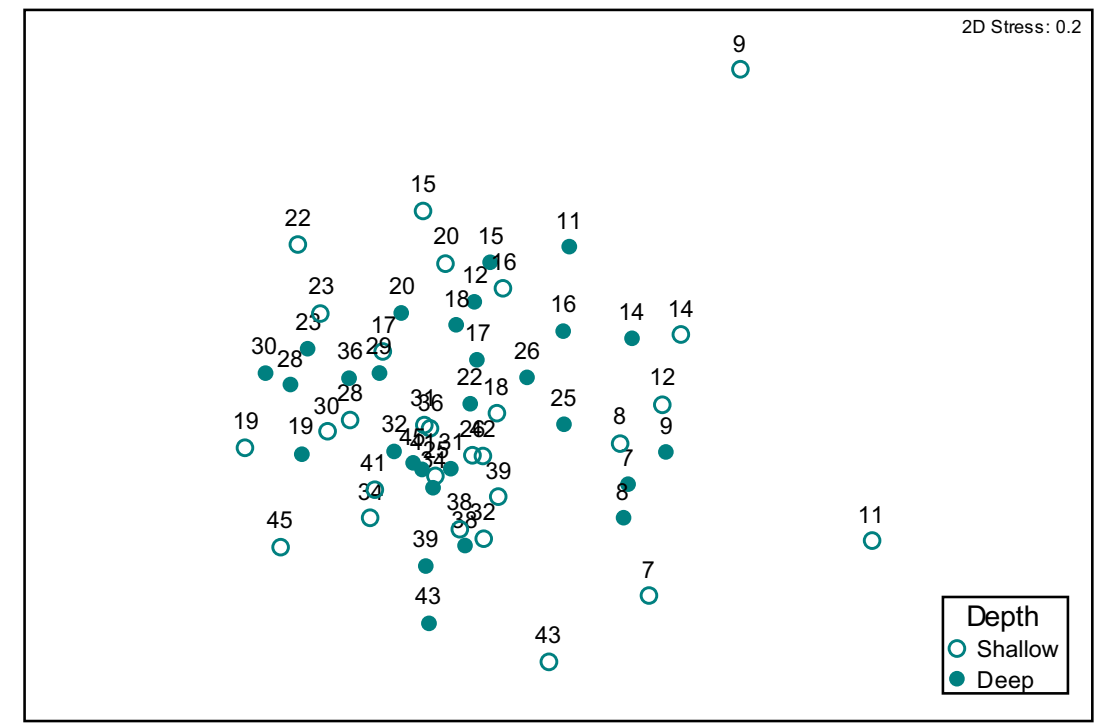

b)

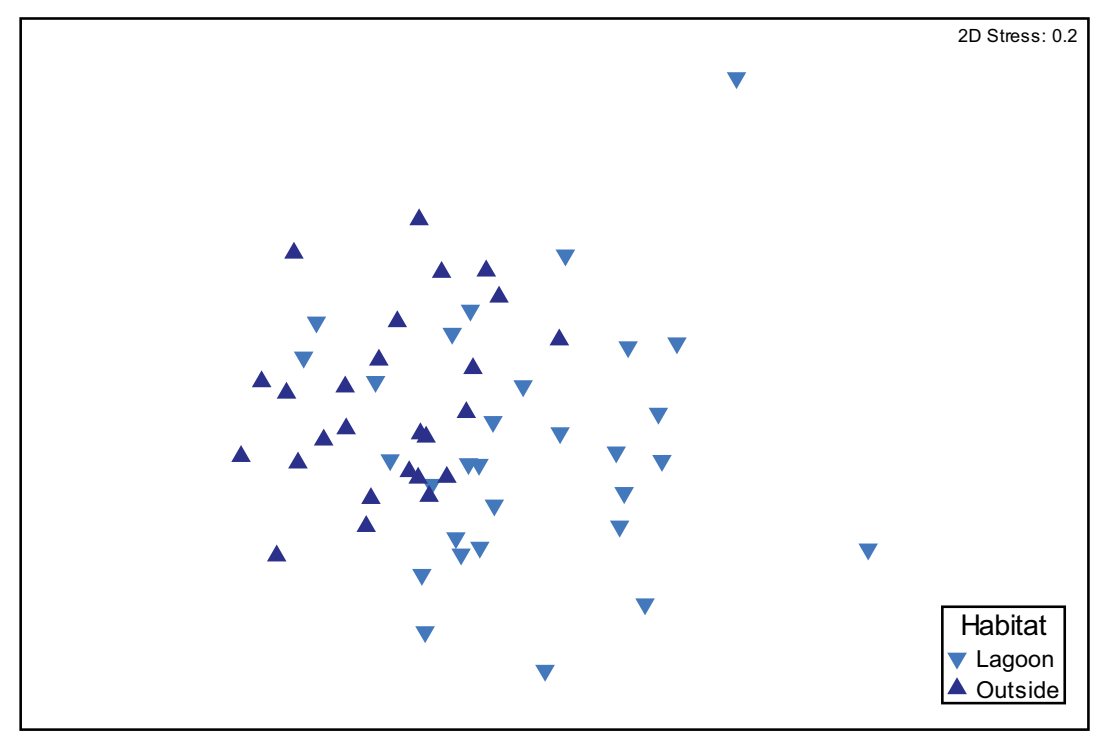

c)

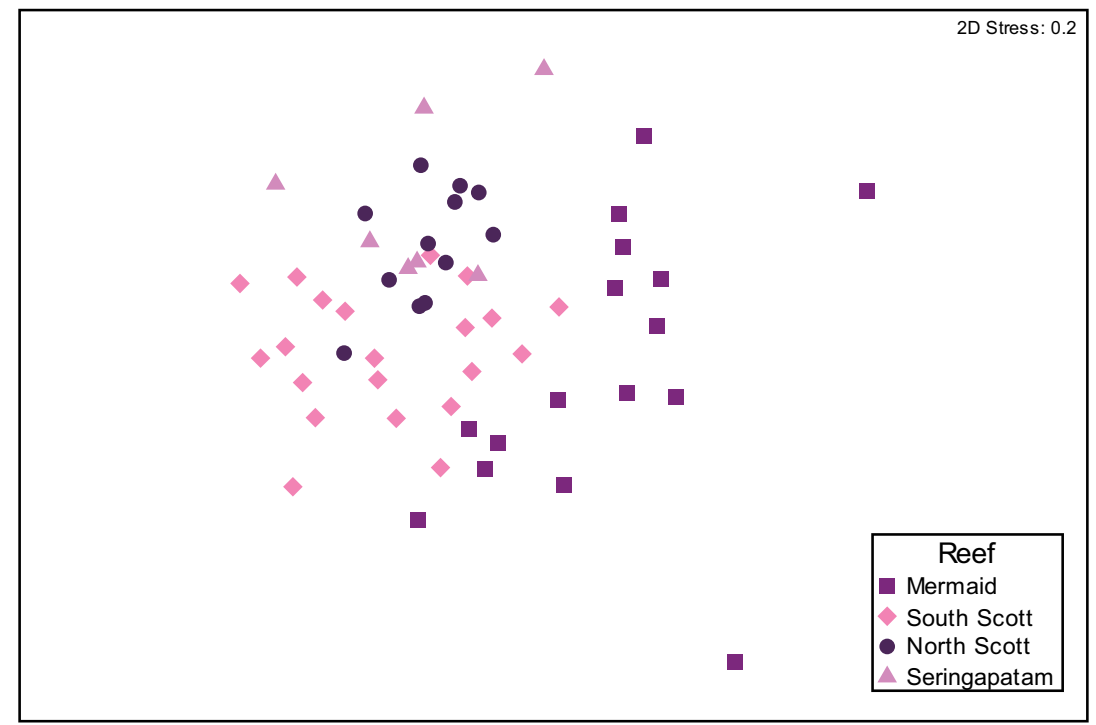

Figure 5 Two-dimensional ordination of crustacean taxa from subtidal stations on north-west Australian reefs, a) depth and station number, b) habitat and c) reef. 
Table 6 PERMANOVA results for lagoon and outer reef habitats only. a) main test, b) pairwise tests

a) main test b) pairwise tests

\begin{tabular}{|c|c|c|c|c|c|c|c|c|}
\hline Source & $\mathrm{df}$ & SS & MS & Pseudo-F & $\mathrm{P}$ (perm) & Groups & $t$ & $\mathbf{P}($ perm) \\
\hline Reef & 3 & 31569 & 10523 & 4.083 & 0.001 & Lagoon & & \\
\hline Habitat & 1 & 8094.5 & 8094.5 & 3.140 & 0.002 & Mermaid, South Scott & 2.171 & 0.001 \\
\hline Depth & 1 & 4170.5 & 4170.5 & 1.618 & 0.074 & Mermaid, North Scott & 2.226 & 0.001 \\
\hline Reef $x$ Habitat & 3 & 16011 & 5337 & 2.071 & 0.001 & Mermaid, Seringapatam & 1.544 & 0.005 \\
\hline Reef $x$ Depth & 3 & 6357.9 & 2119.3 & 0.822 & 0.776 & South Scott, North Scott & 1.963 & 0.002 \\
\hline Habitat $x$ Depth & 1 & 2551.5 & 2551.5 & 0.990 & 0.445 & South Scott, Seringapatam & 1.507 & 0.014 \\
\hline Reef $x$ Habitat $x$ Depth & 3 & 5272.8 & 1757.6 & 0.682 & 0.925 & North Scott, Seringapatam & 1.356 & 0.08 \\
\hline Residual & 40 & $1.03 \mathrm{E}+5$ & 2577.5 & & & & & \\
\hline \multirow[t]{7}{*}{ Total } & 55 & $1.85 \mathrm{E}+5$ & & & & Outer Reef & & \\
\hline & & & & & & Mermaid, South Scott & 1.727 & 0.003 \\
\hline & & & & & & Mermaid, North Scott & 2.074 & 0.003 \\
\hline & & & & & & Mermaid, Seringapatam & 1.969 & 0.029 \\
\hline & & & & & & South Scott, North Scott & 1.607 & 0.009 \\
\hline & & & & & & South Scott, Seringapatam & 1.393 & 0.025 \\
\hline & & & & & & North Scott, Seringapatam & 1.502 & 0.045 \\
\hline
\end{tabular}

by habitat by depth, habitat by depth, and reef by depth interactions were all not significant (Table 6a).

A clearer picture of the differences among reefs was obtained by pooling the two depths sampled at each station and examining the reef dissimilarities for each habitat. The crustacean assemblages in lagoons were very different at Mermaid Reef compared to those from the other atolls (Figure 6a). Three of the stations at South Scott grouped with lagoon stations from North Scott and Seringapatam reefs, and there is a north/south gradient evident on the plot. Two of the South Scott stations (stn 23, group a and stn 29, group c) formed their own groups.

Six of the top ten species contributing to the similarities within the groups are obligate coral associates (Trapezia guttata, Tetralia sp.1, T. nigrolineata, T. glaberrima, Haplocarcinus marsupialis and Calcinus minutus) (Figure 6b). Mermaid Reef lagoon stations (Group b) were the least influenced by these coral associates and separated out largely due to the dominance of the xanthid Chlorodiella? cytherea (>25\%) and the occurrence of the xanthid Psaumis ? cavipes, the latter species not being present at any of the other reefs. Overall, the percentage composition of species driving similarity within Group b is markedly different from the other three groups. Station similarity in Group d, the northern reefs collective group, was strongly influenced by coral associates with five of the nine discriminating species being coral associates and comprising greater than $50 \%$ of the group's composition. Two of the species, Trapezia guttata and Haplocarcinus marsupialis, were not dominant within the other groups. Separation of the two single station groups at South Scott (stn 23, group a, and stn 29, group c) was driven by the strong influence of rare species $(80 \%$ and $>80 \%$ respectively). The three discriminating species for both groups are the same and are also common with Group d. Only one of the species is shared with the Mermaid Reef group.

The crustacean assemblages at outer reefs were very similar across atolls and no significant groupings were formed (Figure 7a). However, some difference is evident in the Mermaid Reef stations, which are well separated from the other reef stations, and evidence of a north/south change in communities in the more northern reefs.

Examination of the top ten species contributing to similarity within each reef supports the observed separation of the Mermaid outer reef stations (Figure 7b). The coral associated hermit crab Calcinus minutus was common to all reefs. Only three species, Trapezia tigrina, Dardanus lagopodes and Calcinus minutus, contributed to similarities at Mermaid Reef and comprised 75\% of the species composition of the outer stations. Similarity of outer reef assemblages of South Scott, North Scott and Seringapatam reefs was determined by eight, seven and six species respectively. Two species, Tetralia sp. 1 and T. glaberrima, were common drivers to all three northern reefs. Three species, Trapezia lutea, Calcinus lineapropodus and Dardanus lagopodes, were 
a)

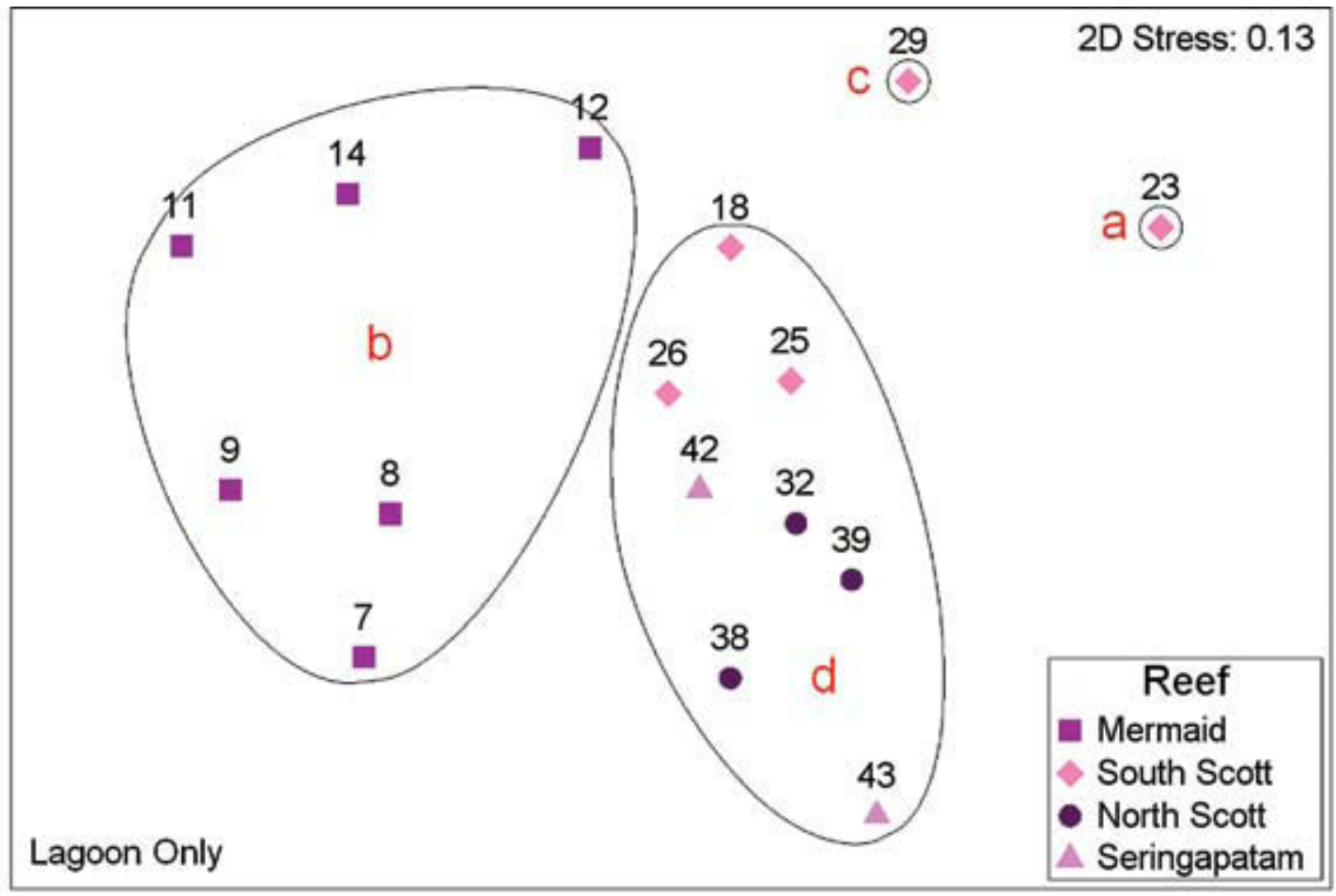

\begin{tabular}{lll|} 
b) & $\square$ Tetralia glaberrima & $\square$ Tetralia sp. 1 \\
$\square$ Psaumis ? cavipes & $\square$ Calcinus latens \\
$\square$ Calcinus minutus & $\square$ Hapalocarcinus marsupialis \\
$\square$ Tetralia nigrolineata & $\square$ Trapezia guttata \\
$\square$ Calcinus lineapropodus & $\square$ Chlorodiella ? cytherea \\
\hline
\end{tabular}

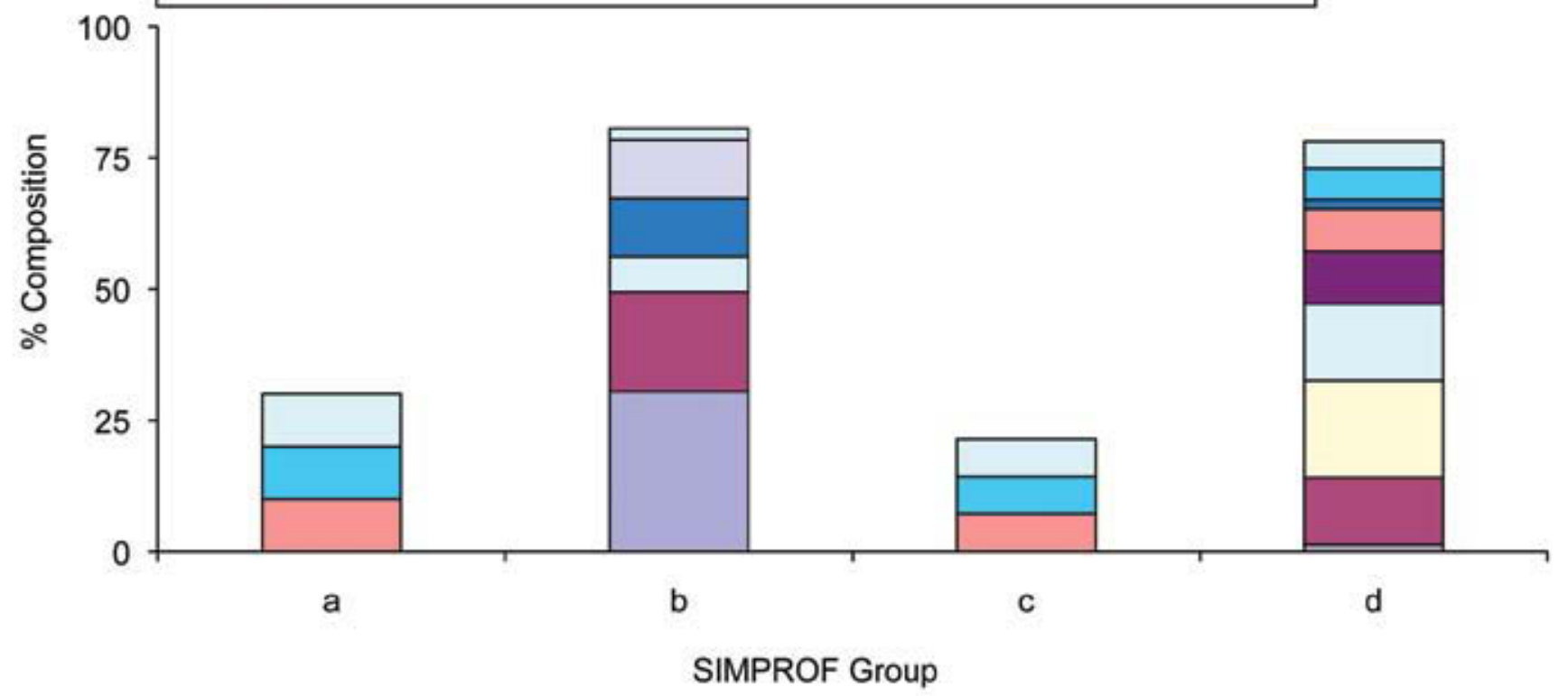

Figure 6. a) Two-dimensional ordination of lagoon stations, depth has been pooled. Clusters were significant (SIMPROF, $\mathrm{p}<0.05)$. b) Top ten taxa that contributed to the similarity within each group (SIMPER). 
a)

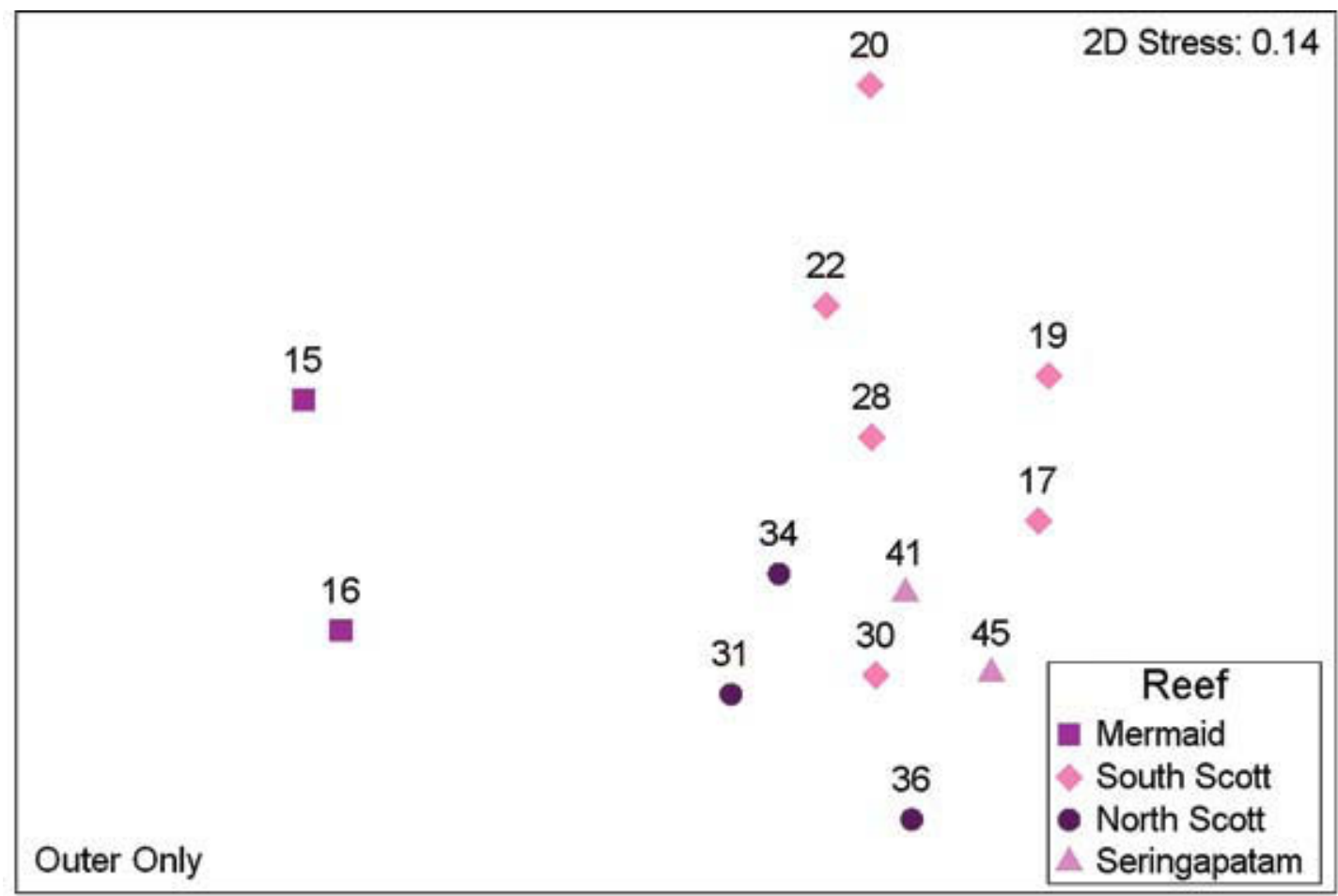

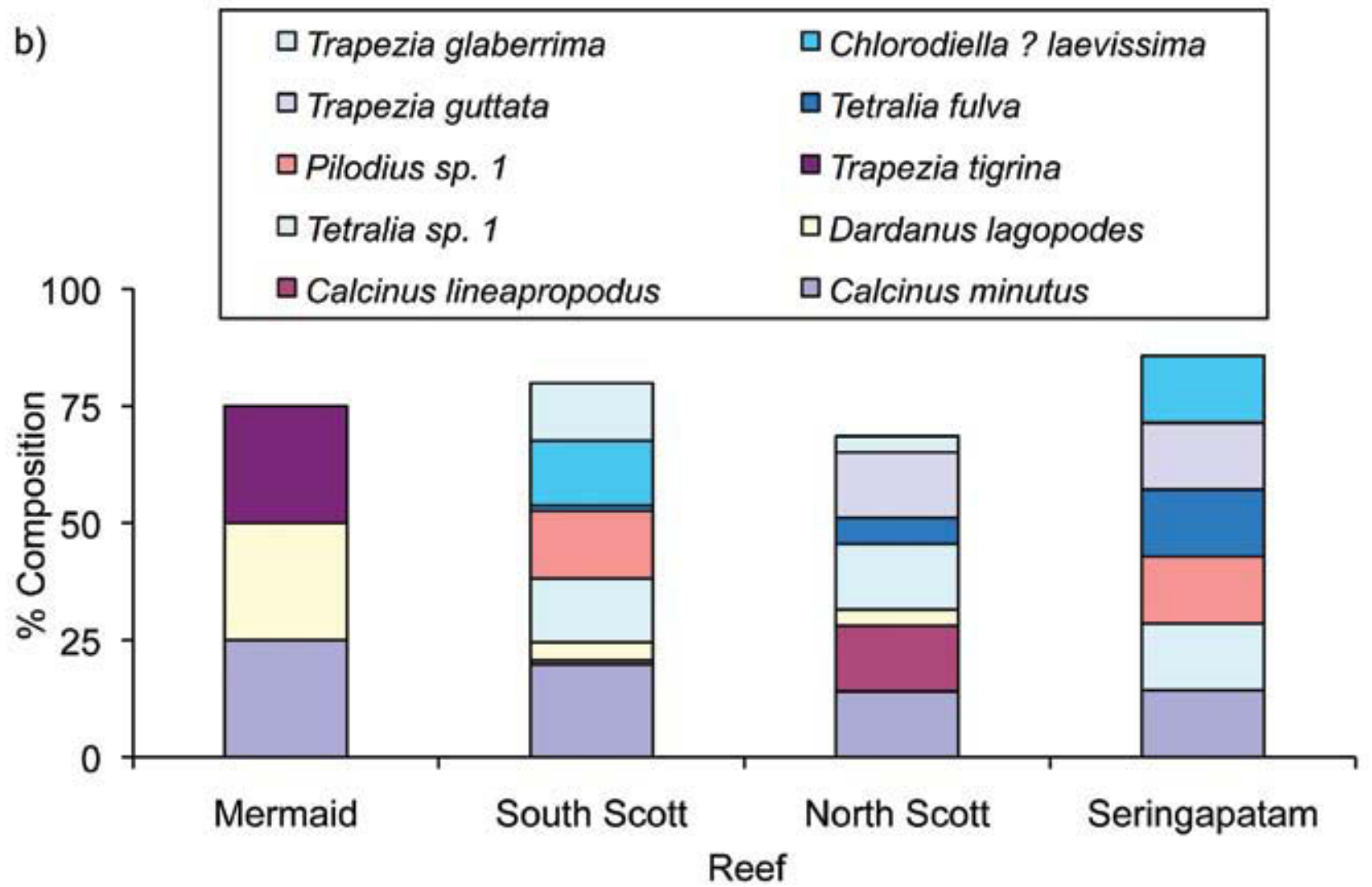

Figure 7 a) Two-dimensional ordination of outer reef stations, depth has been pooled. There was no significant clustering of stations in this habitat (SIMPROF, $\mathrm{p}<0.05)$. b) Top ten taxa that contributed to the similarity within each reef (SIMPER). 


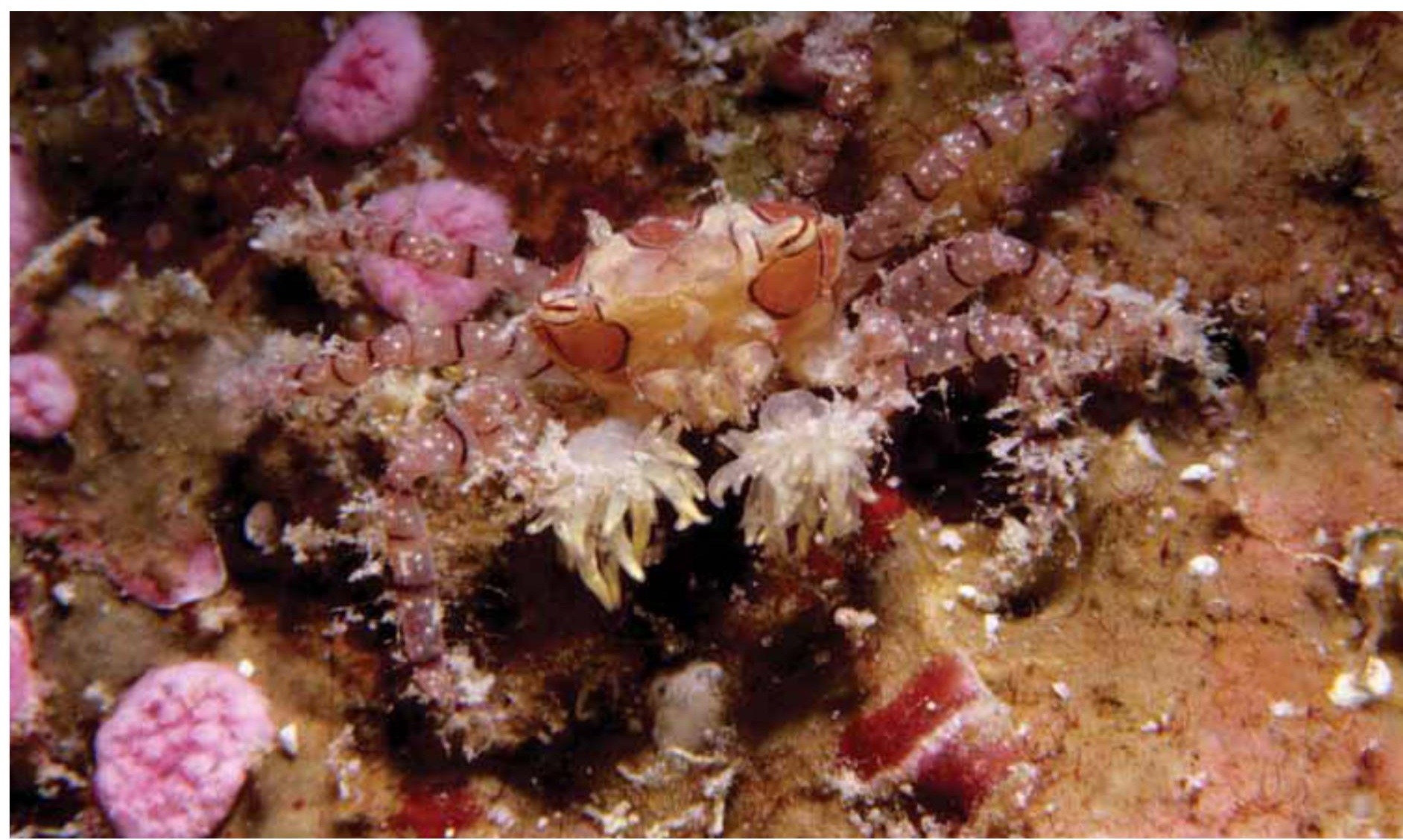

Above: Boxer crab, Lybia tesselata (Latreille, 1812), can be found under coral slabs. (Photo: Clay Bryce)

shared drivers of similarity for South Scott and North Scott reefs stations. The latter species also contributed to similarity at Mermaid Reef. South Scott and Seringapatam reefs shared two species, Chlorodiella ? laevissima and Pilodius sp. 1. One species, Trapezia guttata, was shared by the closely situated North Scott and Seringapatam reefs.

\section{DISCUSSION}

\section{Species richness}

The increased number of species recorded in this survey compared with previous studies is due to increased sampling effort and the close examination of a variety of substrates. The fact that many previously recorded species have been collected again at the same location is encouraging and with completion of all species identifications the discrepancy between previous collections and repeat collections is expected to further diminish.

Comment on temporal changes in the crustacean communities between surveys is not practical as previous collections were limited. Nonetheless, between the first faunal surveys (early 1980s and 1990s) and the 2006 survey significant natural events, such as cyclonic activity, have occurred and led to the destruction of corals and physically altered the reefs. It would, therefore, be expected that some change should also be visible in the crustacean fauna. Firstly, these anticipated changes to the fauna could have been expressed in abundance rather than in diversity values, which highlights the need to include abundance studies in future surveys. Abundance studies would need to be targeted on specific taxa. For example, a study of the abundance of trapeziid crabs per area would be a good measure of the potential effects that coral damage could have on these crustaceans. Secondly, each species defines an ecological niche, which is potentially affected by change and the more species recorded the more likely that minor changes can be detected. The high diversity presented in this survey will therefore provide a good baseline and starting point for future monitoring programs.

The Xanthidae have long been recognised as a strong element of coastal reef communities. Previous collections from Scott, Seringapatam and Ashmore reefs, as well as Cartier Island indicated this pattern is also true of the northwestern Australian shelf atolls, and certainly the high diversity recorded in the present study strongly supports this. The Xanthidae is the most diverse crab family in Australian waters, reaching its highest diversity in shallow reef communities (Davie, 2002). The family encompasses a broad range of trophic levels and associations with substrate types and the recorded high diversity during the survey likely reflects this ability to fill 


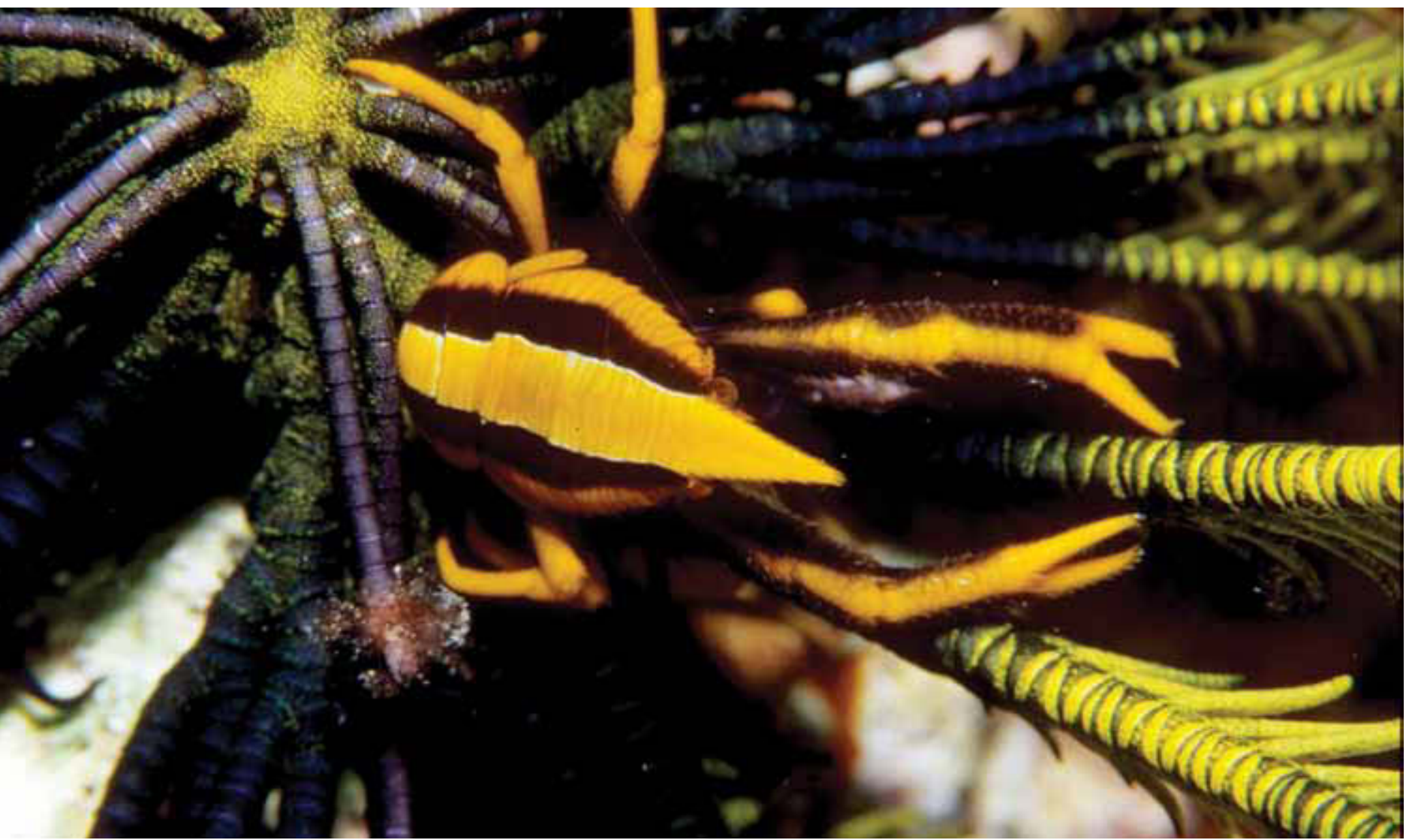

Above: The shrimp, Allogalathea elegans (Adams \& White, 1848) is only found on crinoid seastars. (Photo: Clay Bryce)

many ecological niches within a habitat. The large proportion of rare species (occurring at three or less stations) suggests the composition of the family is highly variable between stations. A high occurrence of rare species in the north-west reef communities would also indicate that to adequately sample xanthids a greater number of sample sites are required. The less sampled reefs of North Scott and Seringapatam reefs recorded a considerably lower diversity in this family.

The painted rock lobster, Panulirus versicolor (Latreille, 1804), is the only species of rock lobster known from the reefs. Live specimens were recorded only from North and South Scott reefs and all were juveniles. A single carapace of a juvenile was also collected from Mermaid Reef, Rowley Shoals, indicating the species occurs there but possibly in low numbers. Berry and Morgan (1986) did not record the species from the Rowley Shoals during the WA Museum 1984 survey and suggested there may be too many predators of spiny lobsters present, such as large serranid fishes, for the species to exist in the Rowley Shoals. However, high numbers of these fishes also occur in coastal waters where spiny lobsters are abundant (B. Hutchins, pers. comm.). It remains unknown as to why only juveniles of $P$. versicolor were recorded. While adults of the species are known to tolerate slightly less turbid conditions than juveniles, the known suitable habitats for both life history phases were sampled adequately during this present expedition. If recruitment of spiny rock lobster larvae to these offshore reefs is low, predation may be enough to keep numbers of individuals low. These outer-shelf atolls are under the influence of the Indonesian Throughflow, the warm water body that pushes through the Indonesian Archipelago to eventually form the Leeuwin Current (Hutchins, 2001). Thus the recruitment source for the atolls is likely to be from the Indonesian Archipelago. This fact would help to explain the extremely rare occurrence of the species at Mermaid Reef, which experiences a reduced impact from the current due to the reef's distance from the current source. Further investigations are nevertheless required into current strength and flow patterns from the Indonesian Archipelago to the atolls before any conclusions can be made regarding lobster recruitment.

\section{Distribution}

Mermaid Reef is situated $400 \mathrm{~km}$ south-west of Scott Reef and was the most southerly reef surveyed. It is therefore not surprising that results presented by the multidimensional scaling analysis and PERMANOVA established a clear separation of the Mermaid Reef communities from the more northerly Scott and Seringapatam reefs. This was 
particularly true of the lagoon stations, where Mermaid Reef stations were significantly different (SIMPROF, $\mathrm{p}<0.05$ ) from the stations at the other reefs. Compared to the other reefs surveyed Mermaid Reef has suffered less environmental disturbance from high sea water temperatures than the more northerly reefs (Gilmour et al., 2007). Nor has the reef been subjected to the same levels of fishing pressure as the northern reefs due to its status as a marine national nature reserve since 1991 (DEWHA, 2009). Furthermore, the frequency and ferocity of cyclonic events appears to be lower at Mermaid Reef than experienced at Scott and Seringapatam reefs (Bureau of Meteorology, 2009). Distance from such events may allow for sites within the Mermaid reef system to develop greater site distinctness.

The geographic separation of Mermaid Reef from the northern atolls is likely to result in greater differences in crustacean assemblages than in the other reefs. The life histories of many crustacean species include a long-distance larval dispersal phase. A dilution effect of the Indonesian Throughflow could explain the absence, or reduced influence, of the species at Mermaid Reef with such a life history, and Indo-Malaysian affinities. Castro (2000) suggested that geographic distribution of most species of the brachyuran family Trapeziidae (Trapezia spp.) and Tetraliidae (Tetralia spp. and Tetraloides spp., Castro et al., 2004) is best explained by long distance larval dispersal. Members of these families had a strong presence in the top ten taxa contributing to similarity within reefs, and showed considerable variation in composition between the reefs, the greatest difference being at Mermaid Reef. Serious consideration must be given to the fact that members of these families of crabs are obligate symbionts of reef building, hermatypic corals and other colonial cnidarians. Species of Trapezia are associated with pocilloporid corals and Tetralia and Tetraloides with acroporid corals (Castro \& Titelius, 2007). Their distribution is therefore linked to the distribution and occurrence of their hosts. Along the Western Australian coastline the numbers of species of these families of corals declines at lower latitudes, five species of Pocillopora and 48 species of Acropora have been recorded from Western Australian waters in the Timor Sea and only one species of Pocillopora and two species of Acropora being recorded south of Perth (Veron, 1993). By comparison, 17 species from within the three genera of these crabs have been recorded from Western Australian waters previously and of these only five species occur as far south as Perth (Castro \& Titelius, 2007).

The close proximity of Scott and Seringapatam reefs to one another (approximately $25 \mathrm{~km}$ apart) is evident in the degree of clustering observed between the reef communities in the multidimensional scaling plots. The PERMANOVA results indicated the North Scott lagoon fauna is more similar to Seringapatam Reef despite its closer proximity to South Scott Reef. The open morphology of the South Scott lagoon possibly contributes to this difference (see maps in station and transect data, this volume). The open lagoon of South Scott Reef is likely to reduce differences between lagoon and outer reef environments. It could also explain the separation of the two South Scott lagoon stations from the northern reef collective group in the two-dimensional plots.

There was a strong separation of all reef platform communities from outer reef and lagoonal sites. The fauna encountered on the platforms need to withstand the extreme conditions experienced when the reef is exposed. The diversity of living substrates (such as corals) with which some crustaceans associate is dramatically reduced in such exposed areas. Furthermore, the absence or presence of tidal pools can have a dramatic effect on the species diversity observed in a platform environment. The high variability of platform habitats is evident in the low level clustering of the stations in the multidimensional scaling analysis.

\section{Sampling methods for crustaceans}

Many crustaceans are inherently cryptic, well camouflaged and highly mobile. This "...habit of lurking in crevices..." and when alarmed "... darting with great swiftness through the water..." (Calman, 1911) requires the employment of special collection and extraction methods. It also means that the process of collecting and extracting crustaceans from their substrate, in order to obtain a species record, is more time consuming than the recording of species of other groups.

A fully quantitative method of sampling involving quadrat counts and transect visual surveys was initially trialled for the collection and documentation of crustaceans (stations 1-4), but did not produce the best possible results for recording biodiversity. Collecting particular substrates and thereby capturing the large proportion of crustaceans that live as epi- and endofauna was found to be the most successful method for maximising species richness. Because this type of study is more time consuming than relying mainly on visual recognition of species, a study of abundances was not possible within the timeframe set for each station. Should abundance studies be included in future surveys, it is suggested that these should be based on selected less cryptic and easily identifiable species, such as hermit crabs. One of the main advantages of the substrate sampling method is that species are identified with the habitat they are associated with. This information 
is often missing from faunal surveys but is invaluable in directing future sampling efforts and collection methods, in understanding and interpreting the complexity of ecosystems and in providing topics for future studies into the biology of marine crustaceans. For instance, a study linking the distribution of trapeziid crabs, which inhabit corals, with the distribution and abundance of the host coral species may highlight the dependencies between these two taxa. One of the discoveries made during this survey was a pilumnid crab inhabiting tube-shaped sponges. It would be worthwhile to explore the possible relationship between the sponge and the crab species to investigate the biology of the crab, which is found in breeding pairs within the sponge, apparently forming part of the crabs' reproductive strategy.

The fact that many crustaceans are nocturnal has not been addressed by the collection method employed in this survey. Nocturnal collections would undoubtedly provide a more accurate estimate of crustacean biodiversity and most likely expand the current species list. It would be worthwhile, therefore, to include some night sampling in future surveys. The current sampling regime also does not take into account the biphasic life style of many crustaceans. Many species are known to colonise a particular habitat as juveniles (for example shallow depths) and then migrate to a different habitat (deeper depths) as reproductive adults. As this survey only sampled depths to $12 \mathrm{~m}$ mean sea level the inclusion of sampling to greater depths would increase the chance of discovering adult specimens of species currently only represented by juveniles in this study.

\section{ACKNOWLEDGEMENTS}

The authors are grateful to the staff and crew of the Kimberley Quest I for providing assistance and transportation in the field. Jane Fromont and David McKinney provided a number of field identifications for sponges and corals and were also excellent company on the sometimes long dinghy journeys. Special thanks to Yuki Konishi, Lyle McShane and Mark Salotti who were very helpful in the long task of processing, sorting and documenting the collected material. Thanks to Sue Morrison, Jane Fromont, Peter Castro and Peter Davie for their invaluable comments on the manuscript.

\section{REFERENCES}

Anderson, M., Gorley, R., and Clarke, K. (2008). PERMANOVA+ for PRIMER: Guide to Software and Statistical Methods. PRIMER-E: Plymouth, UK.

Berry, P.F. and Marsh, L.M. (1986). Faunal Surveys of the Rowley Shoals, Scott Reef and Seringapatam
Reef North-western Australia. Records of the Western Australian Museum, Supplement 25.

Bureau of Meterology, 2009. Tropical Cyclones in Western Australia - Climatology. http://www.bom.gov.au/ weather/wa/cyclone/about/climatology.shtml

Calman, W.T. (1911). The life of Crustacea. p. 90, London.

Castro, P. (2000) Biogeography of trapeziid crabs (Brachyura, Trapeziidae) symbiotic with reef corals and other cnidarians. Pp. 65-74. In: J.C. von Kaupel Klein and F.R. Schram (eds), The Biodiversity Crisis and Crustacea: Proceedings of the Fourth International Crustacean Congress, Amsterdam, Netherlands, 20-24 July 1998, vol. 2.CRC Press, 848 pgs.

Castro, P. and Titelius, M.M. (2007). Trapeziidae Miers, 1886 and Tetraliidae Castro, $\mathrm{Ng}$ and Ahyong, 2004 (Crustacea: Brachyura): coral crabs of Western Australia with notes on their biogeography. Records of the Western Australian Museum Supplement no. 73: 315-327.

Castro, P., Ng, P.K.L. and Ahyong, S. (2004). Phylogeny and systematics of the Trapeziidae Miers, 1886 (Crustacea: Brachyura), with a description of a new family. Zootaxa 643: 1-70.

Clarke, K. and Gorley, R. (2006). PRIMER v6: User Manual/Tutorial. PRIMER-E: Plymouth, UK.

Clarke, K. and Warwick, R. (2001). Change in Marine Communities: An Approach to Statistical Analysis and Interpretation. 2nd edition. Primer-E.

Davie, P.J.F. (2002). Crustacea: Malacostraca: Eucarida (Part 2): Decapoda-Anomura, Brachyura. In A. Wells and W.W.K. Houston, editors, Zoological Catalogue of Australia, vol. 19.3B, CSIRO Publishing, Melbourne, xiv +641 pp.

DEWHA, 2009. Management of Mermaid Reef Marine National Nature Reserve. Department of Environment, Water, Heritage and the Arts. http:// www.environment.gov.au/coasts/mpa/mermaid/ management.html

Gilmore, J., Cheal, A., Smith, L., Underwood, J., Meekan, M., Fitzgibbon, B. and Rees, M. (2007). Data compilation and analysis for Rowley Shoals: Mermaid Imperieuse and Clerke Reefs. Prepared for Department of the Environment and Water Resources. Unpublished Report.

Hutchins, J.B. (2001). Biodiversity of shallow reef fish assemblages in Western Australia using rapid a censusing technique. Records of the Western Australian Museum 20: 247 - 270.

Morgan, G.J. and Berry, P.F. (1993). Part 5. Decapod Crustacea of Ashmore Reef and Cartier Island. In Berry, P.F. (ed) Marine Faunal Surveys of Ashmore and Cartier Island North-western Australia. Records of the Western Australian Museum, Supplement 44, 47-51.

Ng P., Guinot D., Davie P. (2008). Systema Brachyurorum: Part I. An annotated checklist of extant Brachyuran crabs of the world. The Raffles Bulletin of Zoology 17: $1-286$.

Veron, J.E.N. (1993). A biogeographic database of hermatypic coral species of the central Indo-Pacific, genera of the world. Australian Institute of Marine Science Monograph Series 10: 1-433. 